\title{
The OCO-3 mission: measurement objectives and expected performance based on 1 year of simulated data
}

\author{
Annmarie Eldering ${ }^{1}$, Thomas E. Taylor ${ }^{2}$, Christopher W. O'Dell ${ }^{2}$, and Ryan Pavlick ${ }^{1}$ \\ ${ }^{1}$ Jet Propulsion Laboratory, California Institute of Technology, Pasadena, CA 91109, USA \\ ${ }^{2}$ Cooperative Institute for Research in the Atmosphere, Colorado State University, Fort Collins, CO 80521, USA
}

Correspondence: Annmarie Eldering (eldering@jpl.nasa.gov)

Received: 9 October 2018 - Discussion started: 5 November 2018

Revised: 5 March 2019 - Accepted: 22 March 2019 - Published: 15 April 2019

\begin{abstract}
The Orbiting Carbon Observatory-3 (OCO-3) is NASA's next instrument dedicated to extending the record of the dry-air mole fraction of column carbon dioxide $\left(\mathrm{XCO}_{2}\right)$ and solar-induced fluorescence (SIF) measurements from space. The current schedule calls for a launch from the Kennedy Space Center no earlier than April 2019 via a Space-X Falcon 9 and Dragon capsule. The instrument will be installed as an external payload on the Japanese Experimental Module Exposed Facility (JEM-EF) of the International Space Station (ISS) with a nominal mission lifetime of 3 years. The precessing orbit of the ISS will allow for viewing of the Earth at all latitudes less than approximately $52^{\circ}$, with a ground repeat cycle that is much more complicated than the polar-orbiting satellites that so far have carried all of the instruments capable of measuring carbon dioxide from space.

The grating spectrometer at the core of OCO-3 is a direct copy of the OCO-2 spectrometer, which was launched into a polar orbit in July 2014. As such, OCO-3 is expected to have similar instrument sensitivity and performance characteristics to OCO-2, which provides measurements of $\mathrm{XCO}_{2}$ with precision better than $1 \mathrm{ppm}$ at $3 \mathrm{~Hz}$, with each viewing frame containing eight footprints approximately $1.6 \mathrm{~km}$ by $2.2 \mathrm{~km}$ in size. However, the physical configuration of the instrument aboard the ISS, as well as the use of a new pointing mirror assembly (PMA), will alter some of the characteristics of the OCO-3 data compared to OCO-2. Specifically, there will be significant differences from day to day in the sampling locations and time of day. In addition, the flexible PMA system allows for a much more dynamic observation-mode schedule.
\end{abstract}

This paper outlines the science objectives of the OCO-3 mission and, using a simulation of 1 year of global observations, characterizes the spatial sampling, time-of-day coverage, and anticipated data quality of the simulated L1b. After application of cloud and aerosol prescreening, the L1b radiances are run through the operational L2 full physics retrieval algorithm, as well as post-retrieval filtering and bias correction, to examine the expected coverage and quality of the retrieved $\mathrm{XCO}_{2}$ and to show how the measurement objectives are met. In addition, results of the SIF from the IMAPDOAS algorithm are analyzed. This paper focuses only on the nominal nadir-land and glint-water observation modes, although on-orbit measurements will also be made in transition and target modes, similar to OCO-2, as well as the new snapshot area mapping (SAM) mode.

\section{Introduction}

As called for in NASA's Climate Architecture Report (June 2010), the Orbiting Carbon Observatory-3 (OCO-3) was built from spare parts during the construction of OCO-2 to be made available as an instrument of opportunity. After assessment of various options, the decision was made in 2013 to design and build the OCO-3 payload for operation on the International Space Station (ISS). The primary scientific objective of OCO-3 is to provide global, dense, high-precision measurements of the dry-air mole fraction of column carbon dioxide $\left(\mathrm{XCO}_{2}\right)$ and solar-induced fluorescence (SIF) from space. A planned 3-year lifetime aboard the ISS will allow for continuation of the international measurement record of $\mathrm{CO}_{2}$ that began in earnest with the Japanese GOSAT satellite 
(January 2009 to present) (Kuze et al., 2009), followed by NASA's OCO-2 (July 2014 to present), the Chinese TANSAT (December 2016 to present) (Yang et al., 2018), and most recently by GOSAT-2 (launched 29 October 2018) (Nakajima et al., 2012). Furthermore, a 2019 launch of OCO-3 with a 3-year mission lifetime would provide overlap for future planned endeavors such as MicroCARB from CNES (planned 2021 launch) (Buil et al., 2011) and possibly even with the NASA GeoCARB mission (Moore III et al., 2018), which has a planned mid-2022 launch. Because of the relatively small variations in atmospheric $\mathrm{CO}_{2}$ globally, it is critical to understand how the data products from various sensors intercompare at levels less than their precision, which is $0.1 \%$ for both OCO-2 and OCO-3. It is worth noting that all of the sensors mentioned above are polar orbiting, with the exception of OCO-3 (precessing) and GeoCARB, which is the first planned geostationary observation system for measuring $\mathrm{XCO}_{2}$.

The nominal planned viewing strategy of OCO-3 is to take down-looking nadir-viewing measurements over land to minimize the probability of cloud and aerosol contamination. Over water, measurements will be taken near the specular reflection spot (glint viewing) to maximize the signal over the low-reflectivity surface. However, unlike OCO-2, which performs complex maneuvers of the entire satellite bus to observe ground targets, the OCO-3 instrument will be fitted with an agile 2-D pointing mirror assembly (PMA). This will allow for transitions between the nadir and glint mode of the order of tens of seconds. The PMA will also allow for target-mode observations, similar to those taken by OCO2, typically at Total Column Carbon Observation Network (TCCON) ground sites for use in validation (Wunch et al., 2010). In addition, the PMA will provide the ability to scan large contiguous areas (order $100 \mathrm{~km}$ by $100 \mathrm{~km}$ ), such as cities and forests, on a single overpass. This will be known as snapshot area mapping (SAM) mode and will allow for finescale spatial sampling of $\mathrm{CO}_{2}$ and SIF variations unlike what can be done with any current satellite system. If OCO-2 and OCO-3 operate concurrently, the SAM mode will be used to gather a significant fraction of overlapping data. However, this paper deals exclusively with the two main viewing modes (nadir-land and glint-water), while a detailed discussion of SAM mode is deferred to a companion paper.

The sampling that will be provided by OCO- 3 aboard the precessing ISS will differ significantly compared to the polar orbits of OCO-2 and GOSAT. The overpasses will not always occur at the same local time of day for a given point on the Earth; this has implications with respect to the diurnal cycle of both clouds and aerosols (which contaminate the observations of $\mathrm{XCO}_{2}$ ) and studies of the carbon cycle, which itself has a strong diurnal variation. The precession in time-of-day sampling will be especially informative for the SIF observations with respect to studying the biosphere response (both natural and anthropogenic) to changes in sunlight.
The international record of satellite remote sensing of $\mathrm{CO}_{2}$ has extended across a number of measurement platforms, e.g., SCIAMACHY (2002-2012), Aqua AIRS (2002present), GOSAT (2009-present), and TANSAT (2016present) and is being used to quantify several aspects of the carbon cycle. The $\mathrm{CO}_{2}$ seasonal cycle has been studied with SCIAMACHY and GOSAT data (Buchwitz et al., 2015; Lindqvist et al., 2015; Reuter et al., 2013; Wunch et al., 2013, e.g.,). The GOSAT measurements have been used to characterize a number of relatively large disturbances to the carbon cycle, including reduced carbon uptake in 2010 due to the Eurasia heat wave (Guerlet et al., 2013), larger-than-average carbon fluxes in tropical Asia in 2010 due to above-average temperatures (Basu et al., 2014), and anomalous carbon uptake in Australia (Detmers et al., 2015). In addition, Parazoo et al. (2014) used GOSAT XCO $\mathrm{XCO}_{2}$ and SIF estimates to better understand the carbon balance of southern Amazonia, while Ross et al. (2013) used GOSAT data to obtain information on wildfire $\mathrm{CH}_{4}: \mathrm{CO}_{2}$ emission ratios.

Relative to earlier carbon dioxide measurements from space, OCO-2 is providing a much denser dataset (in both time and space) with higher precision in retrieved $\mathrm{XCO}_{2}$. The publicly available $\mathrm{B} 7$ version of the OCO-2 data (now superseded by B9, available at https://disc.gsfc.nasa.gov/, last access: 5 April 2019) has been used to assess the 2015-2016 global carbon cycle (Crowell et al., 2019) and to quantify changes in tropical carbon fluxes (Liu et al., 2017) and the equatorial Pacific Ocean (Chatterjee et al., 2017) due to the strong 2015 El Niño. Both Nassar et al. (2017) and Schwandner et al. (2017) highlighted localized sources detected by OCO-2, while Eldering et al. (2017b) provided an extensive global view of atmospheric carbon dioxide as observed from OCO-2 after its first 18 months in space.

In order to continue the international measurement record of global carbon dioxide from space, NASA plans to operate OCO-3 from the ISS for a period of about 3 years. The launch date at the time of writing is scheduled for 26 April 2019 from the Kennedy Space Center in Florida, USA. Since there are a number of new considerations related to the unique viewing and sampling from this platform, it is desirable to study the expected performance of the instrument prior to launch. To do this we generated one full year of simulated OCO-3 measurements, on which we ran the current versions of the OCO-2 prescreeners and $\mathrm{XCO}_{2}$ retrieval algorithm, as well as the post-processing quality filtering and bias correction. The bulk of this paper is based on these simulations to evaluate expected data quality and data density from OCO-3 aboard the ISS.

The paper is organized as follows. Section 2 provides an overview of the OCO-3 mission, the science objectives, and planned measurement modes. In Sect. 3, the generation of 1 year of simulated L1b radiances using realistic geometry, instrument characteristics, and meteorology is detailed. Section 4 briefly overviews the various algorithms (prescreeners and $\mathrm{XCO}_{2}$ retrieval) and methodologies (filtering and bias 
correction) employed in this work. An analysis of the results is presented in Sect. 5. Particular focus is given to the temporal and spatial coverage, expected signal-to-noise ratios, and $\mathrm{XCO}_{2}$ and SIF errors. Finally, Sect. 6 provides a summary of the expected performance of the OCO- 3 mission based on these simulations.

\section{The OCO-3 science objectives and measurement overview}

Like OCO-2, the OCO-3 mission has been designed to collect a dense set of precise measurements of $\mathrm{XCO}_{2}$ with a small footprint. The scientific objective of the mission is to quantify variations of $\mathrm{XCO}_{2}$ with the precision, resolution, coverage, and temporal stability needed to improve our understanding of surface sources and sinks of carbon dioxide on regional scales ( $\simeq 1000 \mathrm{~km}$ by $1000 \mathrm{~km})$ and the processes controlling their variability over the seasonal cycle. The measurement objective is to quantify the dry-air column carbon dioxide ratio (the total column of carbon dioxide normalized by the column of dry air) to better than $1 \mathrm{ppm}$ for collections of 100 footprints, the same objective as OCO-2. The footprint size is equal to or less than $4 \mathrm{~km}^{2}$ and changes in aspect ratio with the viewing geometry. The OCO-3 mission will also provide a measurement of solar-induced fluorescence, again with similar characteristics as OCO-2. As will be discussed in Sect. 3, the sampling characteristic from the ISS will result in changing latitudinal coverage each month such that the regions where sources and sinks can be quantified will vary in time. The nominal measurement operation mode will be to collect data in nadir viewing over land and glint viewing over oceans, with a variable number of target-mode and snapshot area mapping mode measurements integrated each day.

In addition, the OCO-3 mission also has the potential to contribute to carbon cycle science beyond its primary objective. The current plan includes the nearly simultaneous installation of three other instruments aboard the ISS that are focused on various aspects of the terrestrial carbon cycle (Stavros et al., 2017). This includes NASA's Global Ecosystem Dynamics Investigation (GEDI), which is a lidar instrument designed to make observations of forest vertical structure to assess the aboveground carbon balance of the land surface and investigate its role in mitigating atmospheric $\mathrm{CO}_{2}$ in the coming decades (Dubayah et al., 2014; Stysley et al., 2015). NASA/JPL's Ecosystem Spaceborne Thermal Radiometer Experiment on Space Station (ECOSTRESS) will measure evapotranspiration and assess plant stress and its relationship to water availability (Fisher et al., 2015; Hulley et al., 2017). Finally, the Hyperspectral Imager Suite (HISUI) from JAXA will have a multiband spectrometer with a focus on identifying plant types (Matsunaga et al., 2018). The integration of these data, along with OCO-3 measurements of $\mathrm{XCO}_{2}$ and SIF, has the potential to inform our un- derstanding of many aspects of ecosystem processes (Stavros et al., 2017).

An additional enhancement to the OCO- 3 dataset will be provided by the currently operating OCO-2 instrument if its special pointing capability is synchronized with this suite of instruments to view specific ground targets. A second opportunity for OCO-3 relates to the use of the SAM mode to focus on emissions hot spots, such as emissions from cities and power plants or from natural sources such as volcanoes and wildfires. If OCO-2 and OCO-3 operate concurrently, complementary sampling could maximize the insights on the sources and sinks of carbon dioxide.

\subsection{The OCO-3 instrument payload}

At the core of OCO-3 is a three-band grating spectrometer built as a spare for the OCO-2 instrument, which measures sunlight reflected from the Earth (Crisp et al., 2017; Eldering et al., 2017a). Estimates of $\mathrm{XCO}_{2}$ are derived from these spectra using an optimal estimation retrieval method, denoted the Level 2 Full Physics (L2FP) algorithm, that integrates detailed models of the physics of the atmosphere (Bösch et al., 2006; Connor et al., 2008; O’Dell et al., 2012, 2018).

The oxygen $\mathrm{A}$ band $\left(\mathrm{O}_{2}\right.$ A band) is sensitive to absorption by molecular oxygen near $0.76 \mu \mathrm{m}$, while two carbon dioxide bands, labeled here as the weak and strong $\mathrm{CO}_{2}$ bands, are located near 1.6 and $2.0 \mu \mathrm{m}$, respectively. The $\mathrm{O}_{2}$ $\mathrm{A}$ band provides several important pieces of information. $\mathrm{Ab}$ sorption by oxygen molecules is sensitive to the atmospheric path length, allowing for an estimate of the apparent surface pressure, which in turn is used for cloud screening (Taylor et al., 2016), the retrieval of cloud macrophysical properties (Richardson et al., 2019), and to provide a surface pressure estimate within the $\mathrm{XCO}_{2}$ retrieval algorithm (O'Dell et al., 2018). Aerosol scattering in this band informs the $\mathrm{XCO}_{2}$ retrieval algorithm, which necessarily contains aerosol parameters in the state vector (Nelson and O'Dell, 2019). Finally, solar Fraunhofer lines in this spectral band allow for the retrieval of solar-induced fluorescence, a small amount of light emitted during plant photosynthesis (Frankenberg et al., 2012).

The weak $\mathrm{CO}_{2}$ and strong $\mathrm{CO}_{2}$ spectral bands primarily provide sensitivity to carbon dioxide, with peaks at different vertical heights. They are also used as part of the cloud detection scheme since they are sensitive to the wavelength dependence of aerosol extinction. In addition, the $\mathrm{CO}_{2}$ bands allow for a very accurate retrieval of total column water vapor due to the existence of a number of water vapor absorption lines (Nelson et al., 2016a).

The instrument measures at 1016 channels, i.e., wavelengths, in each spectral band, with 160 pixels averaged in groups of 20 along the slit, creating eight spatial footprints per measurement frame. The entrance optics have been modified to reduce the magnification from $2.4: 1$ to $1: 1$ to main- 
tain similar footprint sizes given the lower altitude of the ISS, which typically flies at $\simeq 404 \mathrm{~km}$ compared to OCO-2 at $\simeq 705 \mathrm{~km}$. This magnification change will result in OCO3 footprints that are $<4 \mathrm{~km}^{2}$, comparable to the $3 \mathrm{~km}^{2}$ of OCO-2. The instrument field of view, i.e., the frame, will be approximately 13 or $1.6 \mathrm{~km}$ in width per eight footprints, and the spacecraft motion covers $\simeq 2.2 \mathrm{~km}$ during the $0.33 \mathrm{~s}$ of integration time. The rate of data collection will be approximately 1 million sets of three spectral band measurements per day, before considering the ISS limitations discussed in Sect. 2.3.

The OCO-3 project inherited a fully characterized spectrometer from the OCO-2 project, which was designed for integration on a LeoStar spacecraft. For utilization on the ISS JEM-EF, a number of adaptations were required (Basilio et al., 2013). These include redesign of the thermal system, updates to the electrical system, and updates to the data flow from the instrument to the data processing center at JPL. These changes do not fundamentally change the radiometric characteristics, and therefore the science data quality, so they will not be discussed in this paper. As described in the following section, a new pointing mirror assembly was also required for OCO-3.

\subsection{OCO-3 pointing mirror assembly overview}

A design change that impacts the radiometric characteristics of the data is the addition of a pointing mirror assembly. The PMA is required to allow non-nadir observations from the fixed position on the ISS, unlike the currently operating OCO-2, which maneuvers the entire spacecraft to point. Two important design requirements of the PMA were to allow quick movement through a large range of angles and that the movement not impart any angular dependent polarization or radiance changes in the measurements. To meet these objectives a variation of the pointing system designed for the Glory Aerosol Polarimetry Sensor (APS) (Persh et al., 2010) was selected. The APS system relies on a single pair of matched mirrors in an orthogonal configuration that impart less than $0.05 \%$ change to the polarization (Mishchenko et al., 2007). For the OCO-3 PMA the concept was extended to a two-axis pointing system. There are two elements: one controlling the azimuthal (cross-track) angle and the other controlling the elevation (along-track) angle. Although the PMA itself does not change the polarization of the light more than $0.1 \%$, there are polarization implications, since the image of the slit is rotated as a function of the change in the PMA, primarily driven by the elevation (along-track) angle. It is worth noting that reflected sunlight is naturally polarized by its interaction with the Earth's surface and atmosphere, especially over water.

Early in the mission design, a trade study was performed, evaluating the expected signal with and without the installation of an additional polarization scrambler, i.e., a polarization-nulling optical component. Inserting a scrambler would make the polarization orientation of the incoming light random, regardless of the position of the PMA and the orientation of the instrument slit, but would reduce the signal by nearly $50 \%$. In addition, the analysis showed that a single optical element that could scramble light at all of the OCO-3 wavelengths could not be manufactured and characterized to the required precision. Lastly, the volume and coverage of data with sufficient signal in the no-scrambler case were predicted to be more than sufficient to meet the science objectives. Therefore, OCO-3 will be operated without a polarization scrambler.

As will be discussed in more detail in Sect. 5.1, the PMA is one element that contributes to a change in the overall light throughput of OCO-3 compared to OCO-2. In the $\mathrm{O}_{2}$ A band, each mirror has a reflectivity of $95.4 \%$, so the fourmirror PMA system has an effective transmission of $83 \%$. The weak and strong $\mathrm{CO}_{2}$ band overall transmissions are higher, at $93 \%$ and $95 \%$, respectively.

\subsection{Sampling from the International Space Station - routine measurements}

The ISS orbit is nearly circular about the Earth, with altitudes that range from 330 to $410 \mathrm{~km}$. The planned altitude during the time of OCO-3 operation is $405 \mathrm{~km}$. With a ground-track velocity of $27600 \mathrm{~km} \mathrm{~h}^{-1}\left(7.667 \mathrm{~km} \mathrm{~s}^{-1}\right)$, one orbit around the Earth is completed in about $92 \mathrm{~min}$. The inclination of the orbit is $51.6^{\circ}$, which limits the latitudinal range that can be sampled by OCO-3. These orbital parameters result in a precessing orbit, with the Equator crossing time occurring about 20 min early each day. The effect is that over the course of a year the OCO-3 sampling at a particular geolocation varies across all hours of the day. Many more details of the ISS and its orbit can be found in the technical document (ESA, 2011). Section 3.2 pertains specifically to the ISS orbit parameters.

OCO-3 will dynamically control the viewing mode along each orbit via the PMA, with routine data collection consisting of nadir and glint measurements. The PMA compensates for ISS pitch and roll in real time using the onboard star tracker and Inertial Measurement Unit (IMU). The IMU comprises three fiber-optic gyros and three solid-state accelerometers in a compact package that measures velocity and angle changes in a coordinate system fixed relative to its case. In principle, OCO-3 could operate even when the ISS is rolled $90^{\circ}$ relative to it nominal attitude.

Overland measurements will primarily be made in nadir mode, whereby both the optical path length and statistical probability of observing clouds are minimized. Glint measurements are necessary over the ocean, as the surface reflectivity is not large enough to produce an adequate signal, except in a few cases. A small offset from the true glint spot will be included to avoid saturation of the instrument. While the glint measurements provide a larger signal over oceans, the longer optical path lengths and enlarged footprint of this geometry also make these measurements more sensitive to cloud cover (Miller et al., 2007). 


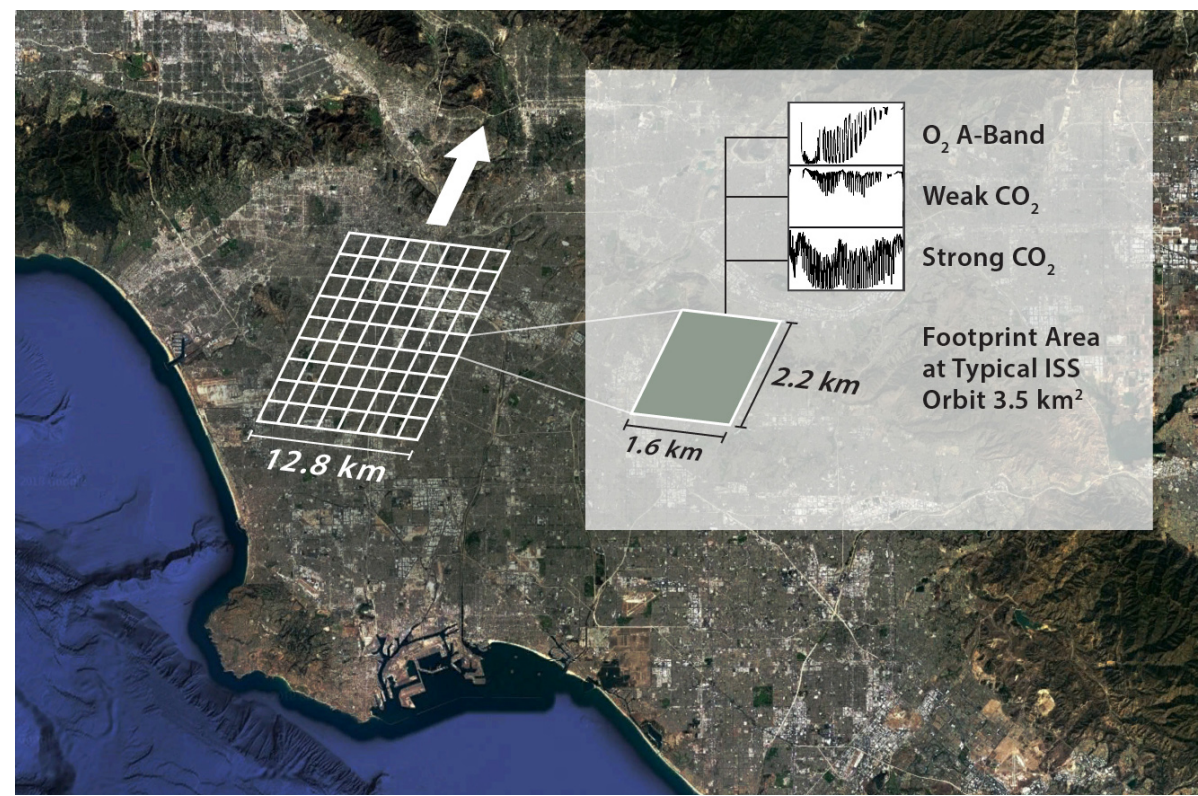

Figure 1. OCO-3 context image depicting nine sequential frames acquired in $3.0 \mathrm{~s}$ in nadir-viewing mode over the Los Angeles basin. Each frame contains eight adjacent footprints in the cross-track direction with a size of $2.2 \mathrm{~km}$ by $1.6 \mathrm{~km}$, yielding a footprint area of approximately $3.5 \mathrm{~km}^{2}$. Each footprint constitutes a sounding, containing high-resolution spectra in the oxygen A, weak $\mathrm{CO}_{2}$, and strong $\mathrm{CO}_{2}$ bands. Image courtesy of Karen Yuen and Laura Generosa at JPL.

The transition time for the PMA is required to be less than $50 \mathrm{~s}$ between nadir and glint modes, which translates into approximately $380 \mathrm{~km}$ along track. In testing with the flight hardware, all moves were made within $10 \mathrm{~s}$, which corresponds to about $75 \mathrm{~km}$ along track. Mission planning assumes the required $50 \mathrm{~s}$ move time, and thus, similar to GOSAT, small land masses in the ocean will be measured in glint mode, while continental-scale areas (areas that will be sampled for more than $200 \mathrm{~s}$ ) will be measured in nadir mode. Unfortunately, this means that most inland freshwater bodies will be observed in nadir mode and will therefore not provide useful retrievals due to low signal-to-noise ratios. This will include substantial bodies of water such as the Great Lakes of North America. However, bodies of water as large as the Mediterranean Sea will be sampled in glint viewing. The sampling strategy is one of the key differences from OCO-2, for which the measurement mode is specified orbit by orbit.

A subtlety of OCO-3 relative to OCO-2 is that, for nadirland observations, the slit will remain perpendicular to the direction of flight since the instrument is not rotated to maintain measurements in the principle plane. This will produce a constant swath width of about $13 \mathrm{~km}$, as depicted in Fig. 1, which provides a best-guess representation of several frames viewing the Los Angeles metropolitan area. The ground footprint for glint-mode measurements, however, will more closely resemble that of OCO-2, as the PMA will rotate to view near the specular reflection point.

\subsection{Target validation measurements}

For the currently operating OCO-2, target-mode measurements are taken over ground validation sites of the Total Carbon Column Observing Network (TCCON) (Wunch et al., 2010, 2011, 2017). The TCCON instruments are groundbased Fourier transform spectrometers that look directly at the sun (thus avoiding the complications of atmospheric scattering phenomena) and are used to derive total column carbon dioxide measurements with similar sensitivity as OCO-2 and OCO-3. The TCCON data are tied to the World Meteorological Organization (WMO) scale for carbon dioxide through routine, ongoing overflights of aircraft equipped with in situ sensors. The mechanics of the target-mode observations of OCO-3 will be very similar to OCO-2, whereby data are collected using a sweeping, or dithering, pattern over the ground-based station. The width of the sampling area is determined by the combination of the instrument field of view and rotation of the footprints, which in turn is determined by the extent of PMA motion. Each target acquisition provides a set of overlapping observations that are used to statistically evaluate the retrieval performance for a range of viewing geometries compared to the static TCCON groundbased measurement. The current OCO-2 mission captures one or two target measurements per day such that the total number gathered over the mission lifetime has been sufficient to perform validation (Wunch et al., 2017). OCO-3 will follow this basic strategy, although for some sites, where there are very few measurements in some seasons, e.g., at high lat- 
itudes in the winter, OCO-3 will potentially take more target measurements per day if it will improve the seasonal coverage for these sites.

\subsection{Snapshot area mapping (SAM) mode measurements}

The agile pointing system of OCO- 3 will also allow for the collection of data in new spatial patterns relative to OCO2. The snapshot area mapping mode has been designed, which is similar to the target-mode observations, but with two-dimensional sweeping, i.e., from side to side as well as back and forth. In this way, an area of the order of $100 \mathrm{~km}$ by $100 \mathrm{~km}$ can be sampled. The types of areas that will be sampled include $\mathrm{CO}_{2}$ emission hot spots, terrestrial carbon focus areas, and volcanos. Based on analysis of fossil fuel emissions and uncertainties of the emissions estimates (Oda and Maksyutov, 2011; Oda et al., 2018), a nominal sampling strategy for the emission hot spots is being developed. Preliminary results suggest that 50 to 100 snapshots per day will be collected, consuming up to 200 of the approximately 650 daylight orbit minutes, i.e., $25 \%$ to $30 \%$ of the data volume. All (or nearly all) of the SAMs will be made over land, especially in the Northern Hemisphere, leading to a vast reduction in the amount of nominal nadir-land data that are actually collected. The SAMs will provide a novel dataset for exploration by the scientific community that is focused on the remote sensing of greenhouse gases and SIF from space. The full details of the new SAM mode will be presented in a paper using on-orbit measurements.

\section{Simulated geometry, meteorology, and L1b dataset}

In this section, we discuss the simulation of OCO-3 data in terms of viewing geometry, meteorology, and observed radiometric quantities such as data density and signal-tonoise ratio (SNR) of the measurements, the latter of which is the primary driver of instrument precision. This will enable a realistic analysis of the effects that the ISS orbit will have on the OCO-3 data products in comparison to the sunsynchronous afternoon orbits of OCO-2. The generation of OCO-3 L1b radiances presented in this paper followed the same basic methodology as that used in previously published work on both GOSAT and OCO-2 (Bösch et al., 2006; O'Brien et al., 2009; O'Dell et al., 2012).

\subsection{Simulated OCO-3 observation geometry}

Actual ISS ephemeris data for the year 2015 were used to provide position and velocity vectors of the space station each second over the course of a year. To create a manageable dataset for this work, samples were taken only once every $10 \mathrm{~s}$, rather than at the true $3 \mathrm{~Hz}$ collection rate of the OCO- 3 instrument. Also, only one sounding per frame, rather than eight, was used since the truth models lack the fidelity neces- sary for such high spatial resolution. The analysis presented in this work focuses on nadir-land and glint-water observation modes only; i.e., it ignores transition, target, and snapshot modes. This provides a baseline of the densest possible nadir and glint data if all the other viewing modes were disabled. As mentioned in Sect. 2.5, it is estimated that as much as $25 \%-30 \%$ of the data volume will be collected in snapshot mode, mostly over Northern Hemisphere land. Some additional small amount, of order of a few percent, will be collected in target and transition modes.

Figure $2 \mathrm{a}$ through $2 \mathrm{~d}$ show the number of measurements as a function of latitude and day of year, with nadir-land (panels $a$ and c) and glint-water (panels b and d) observations shown separately. The data are binned in increments of $1 \mathrm{~d}$ and $2^{\circ}$ latitude. The values in these figures, and in the accompanying discussion, must be inflated by 240 to reflect expected real sounding densities at the full spatiotemporal resolution. Note that the figures in this section use L1b data collection density with no filtering. That is, no cloud-aerosol prescreening or post-L2FP filtering has been performed here, and these topics are discussed in later sections.

The most notable feature of the density data is the sinusoidal pattern with a period of approximately $70 \mathrm{~d}$, yielding $\simeq$ five repeat cycles per year. The nadir-land observation density ranges from close to zero soundings per bin below $\sim 30^{\circ} \mathrm{S}$ latitude (where there is little land) to approximately 25 soundings per bin (per day, per $2^{\circ}$ latitude) southward of $\sim 20^{\circ} \mathrm{N}$ latitude. Northward of $\sim 20^{\circ} \mathrm{N}$ latitude, the sampling density has significant dependences on latitude and time, with a maximum of more than 300 soundings per bin at the northern extremity $\left(\sim 55^{\circ} \mathrm{N}\right)$.

The pattern for glint-water viewing is qualitatively very similar, but with density 2 to 3 times higher than land across most of the subtropics. The data densities can be over 300 soundings per bin at high latitudes near the satellite orbit inflection points. The simulated geometry used in this work takes into account the physical limitations of the PMA due to interference from the solar panels and other constraints on the ISS. These physical restrictions have an especially large impact on the Southern Hemisphere glint data, as seen around DOY 120, 180, and 240 in Fig. 2.

Figure 2e and d show the same data as a subset for the DOY range 60 to 119 (approximately March-April) to highlight the latitude and time dependence of the data collection across most of a single $70 \mathrm{~d}$ repeat cycle. Some interesting features, advantages, and limitations of these collection patterns are presented after the discussion of the seasonal maps that are shown next.

Another way to visualize the spatiotemporal distribution of the data is presented in Fig. 3, which shows seasonal sounding density maps from the simulated dataset, binned at $2^{\circ}$ latitude by $2^{\circ}$ longitude. Here, and elsewhere in the paper, the seasons are defined as December-January-February (DJF), March-April-May (MAM), June-July-August (JJA), and September-October-November (SON). There are just 

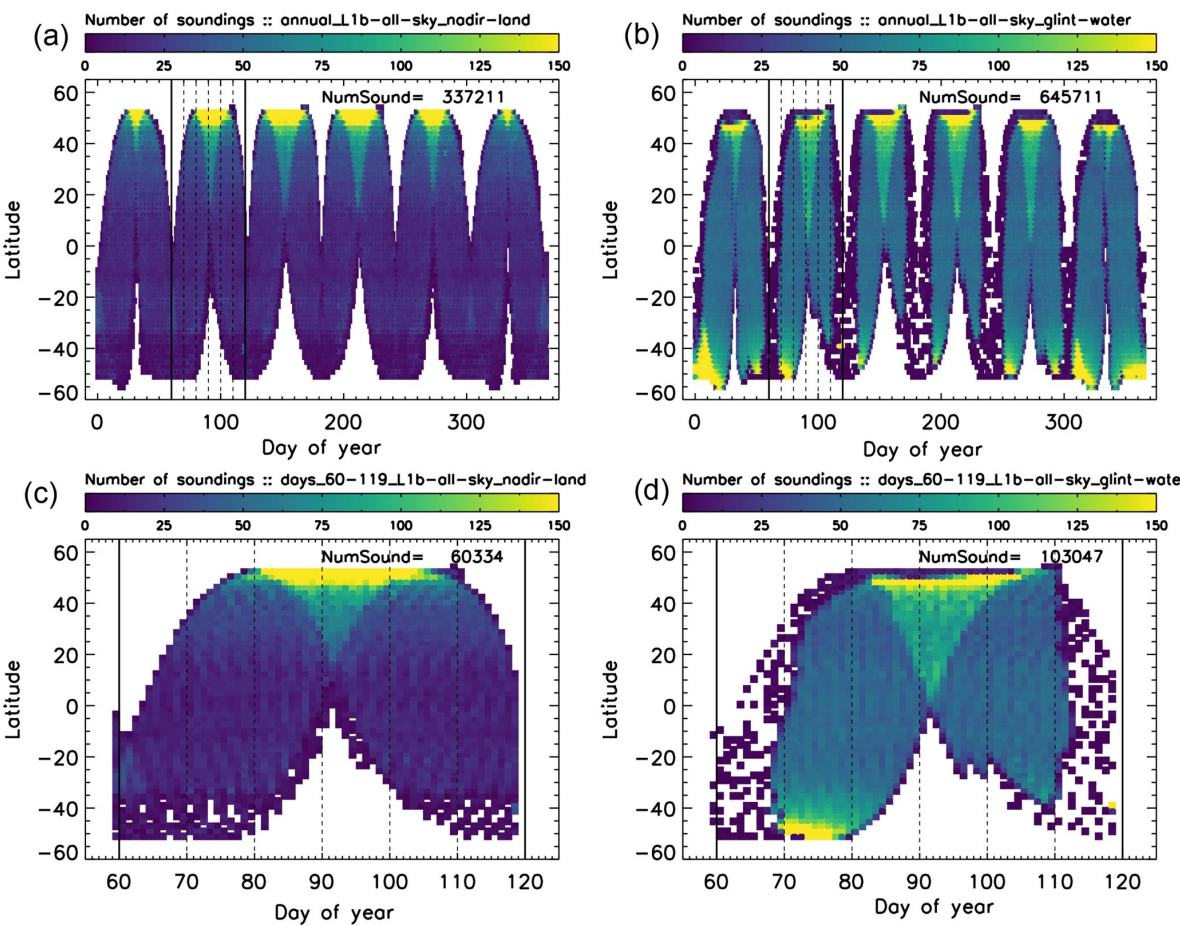

Figure 2. Simulated sounding densities for nadir-land (a, c) and glint-water (b, d) for the annual (a, b) and DOY 60-119 (c, d) datasets. Data are binned in $1 \mathrm{~d}$ by $2^{\circ}$ latitude increments. Values should be inflated by 240 to reflect real expected sounding densities at the full spatial (eight footprints per frame) and temporal $(3 \mathrm{~Hz})$ acquisition rates. To account for the large dynamic range, the density scale has been truncated at 150, although the extreme high latitudes contain up to 300 soundings per bin in some cases.

under a million soundings total for the full year, with approximately 25 soundings in each $2^{\circ}$ bin over most of the globe per season. Presenting the data in this manner accentuates the high density of soundings at the orbit inflection points, although the drift in coverage with seasons is muted. The gaps in data collection so apparent in Fig. 2 are no longer observed when the data have been aggregated monthly or seasonally. This has implications for the spatial and temporal scales of science questions that can be probed with the OCO-3 observations made from the ISS.

Figure 4 uses Hovmöller diagrams to illustrate some of the features of the sampling from the ISS precessing orbit. Panel (a) shows the observation latitude as a function of hours from local noon (HFLN) and day of year (DOY) for the full annual dataset. The dominance of the yellow shades suggests that a large fraction of the soundings are taken at latitudes greater than $50^{\circ} \mathrm{N}$. Panel (b) shows the HFLN as a function of latitude and DOY for the full annual dataset. Most of the observations are taken $\pm 5 \mathrm{~h}$ relative to local solar noon. Here the $\simeq 70 \mathrm{~d}$ repeat cycle is evident, and the precession in observation time as a function of latitude becomes clear.

Figure $4 \mathrm{c}$ and $\mathrm{d}$ show a subset of the data for DOY 60 to 119 (approximately March and April) to highlight some of the detail across a single repeat cycle. $10 \mathrm{~d}$ periods are denoted with vertical lines in the diagrams. The data dropouts due to mechanical interference of the PMA by the ISS are seen at the higher southern latitudes. In general, the diurnal and spatial sampling pattern of OCO-3 aboard the ISS will vary significantly from the more familiar polar-orbiting satellites. This will have implications for the $\mathrm{XCO}_{2}$ and SIF science questions that can be explored.

Figure 5 presents global maps of the sampling pattern for the six sets of 10 sequential days, highlighting both the spatial coverage and time-of-day sampling for a single repeat cycle. These maps clearly show the ascending-descending node variation in time, elucidating the drift in HFLN as a function of day for any given location. The interpretation of this complex sampling pattern by global flux inversion models in an observing system simulation experiment (OSSE), as was performed for OCO-2 by Miller et al. (2007) and for GOSAT by Liu et al. (2014), is an interesting but unexamined issue that is outside of the scope of the current work.

\subsection{Simulated instrument polarization angle and Stokes coefficients}

As unpolarized solar radiation traverses the Earth's atmosphere (twice) prior to incidence upon a spaceborne sensor, interactions with particles, e.g., oxygen molecules and aerosols, as well as reflection off the surface, introduce some amount of polarization. Both the OCO-2 and OCO-3 instruments are sensitive only to the component of radiation polar- 

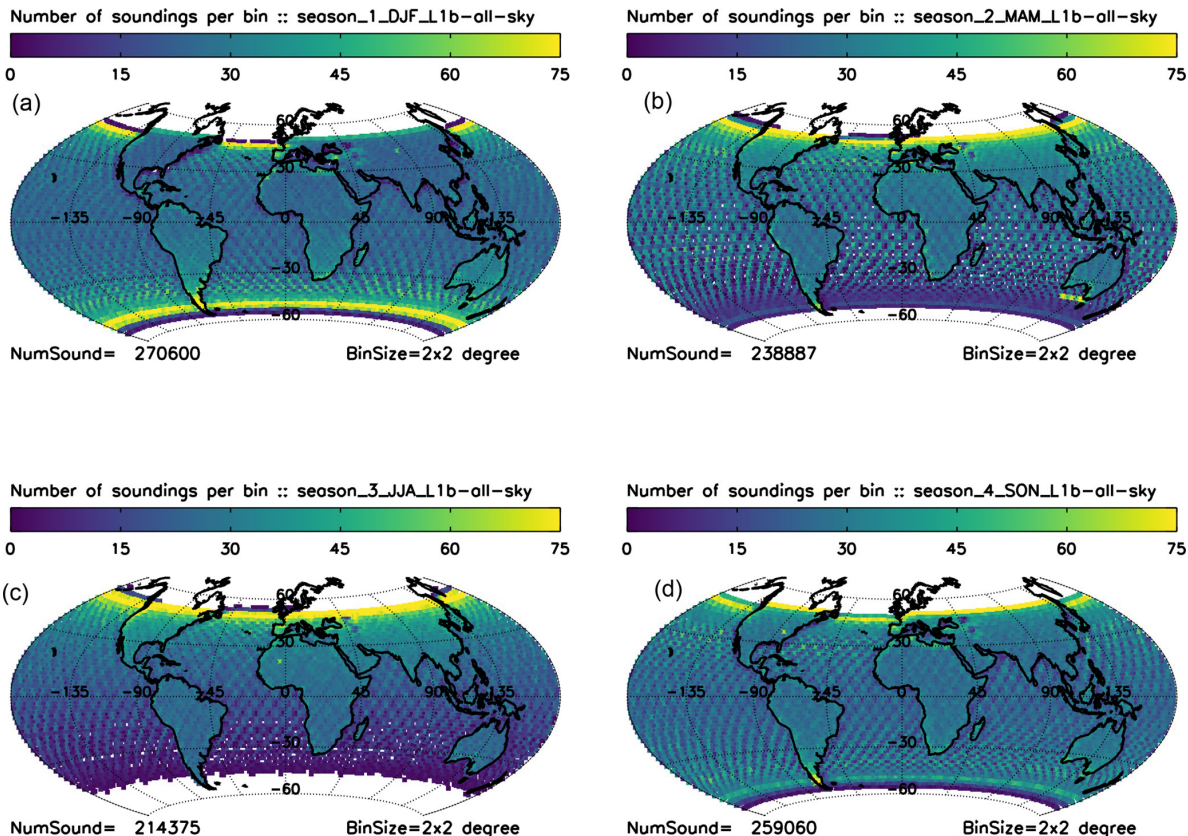

Figure 3. Seasonal L1b sounding density maps for $2^{\circ}$ latitude by $2^{\circ}$ longitude bins. (a) DJF, (b) MAM, (c) JJA, and (d) SON. Values should be inflated by 240 to reflect real expected sounding densities at the full spatial (eight footprints per frame) and temporal ( $3 \mathrm{~Hz}$ ) acquisition rates.
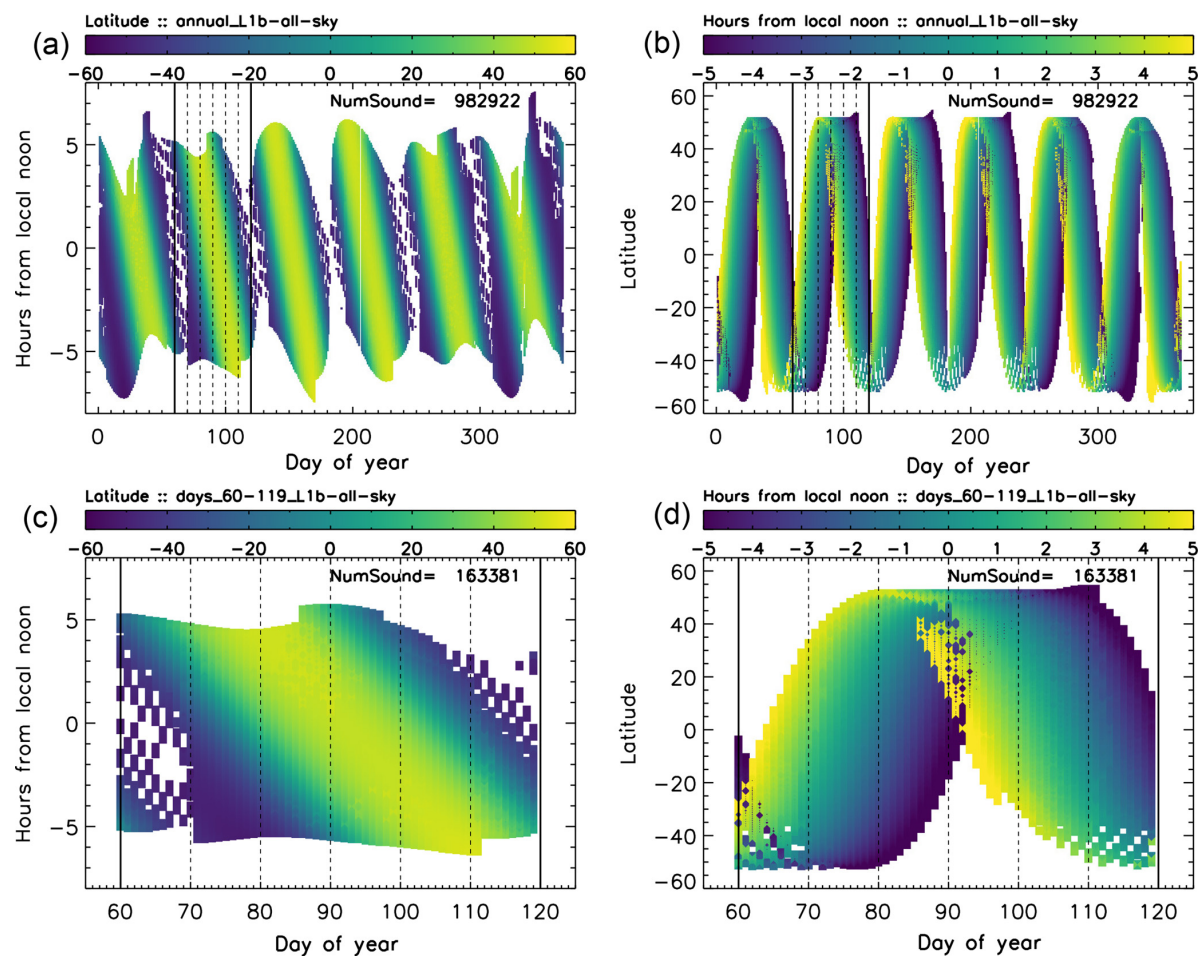

Figure 4. Hovmöller plots showing the observation latitude versus day of year and sampling time relative to local noon (a) and the time relative to local noon versus DOY and latitude (b) for the full year of simulations. Panels (c) and (d) show subsets highlighting the patterns across days 60 to 119 . Values should be inflated by 240 to reflect real expected sounding densities at the full spatial (eight footprints per frame) and temporal $(3 \mathrm{~Hz})$ acquisition rates. 

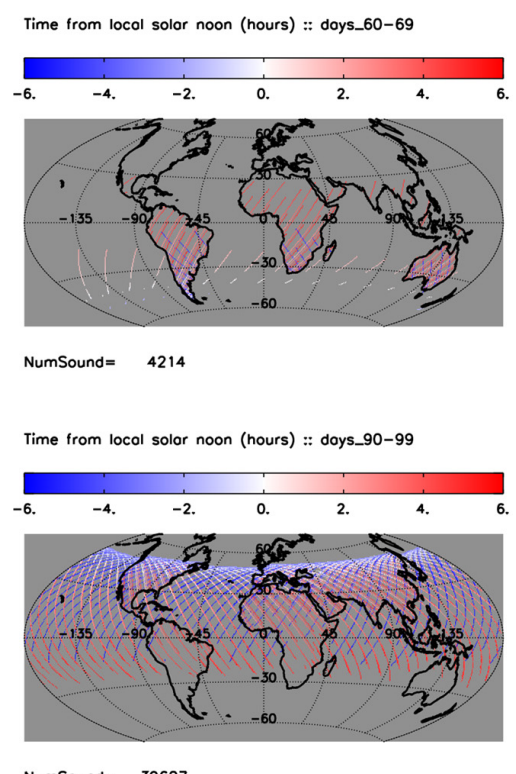

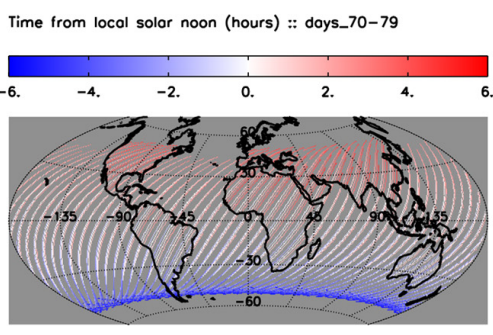

NumSound $=34235$

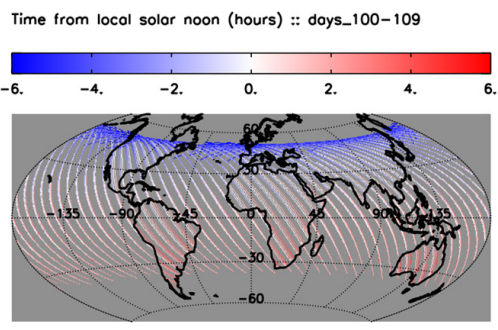

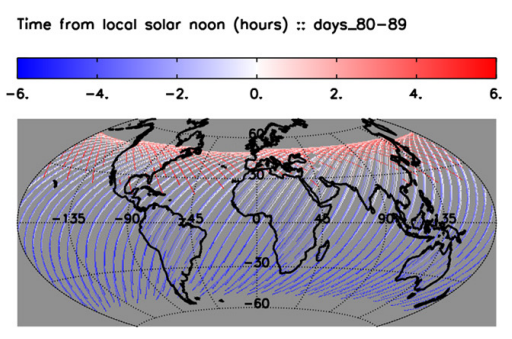

NumSound $=38944$

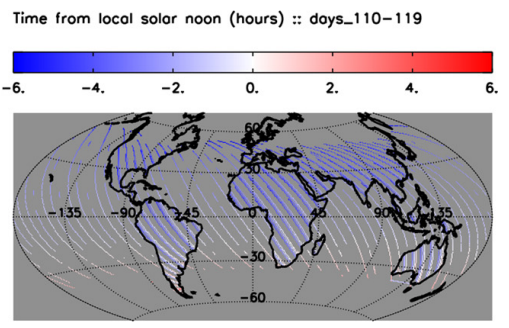

NumSound $=11945$

Figure 5. Simulated OCO-3 sampling pattern for six $10 \mathrm{~d}$ periods, colored by the time in hours relative to local noon. The pixel size of individual footprints has been magnified for viewing purposes.

ized perpendicular to the long axis of the spectrometer slits. ${ }^{1}$ This is critical over strongly polarizing water surfaces but of lesser concern over land surfaces, which are only slightly polarizing. Specifically, the vertically polarized component of light reflecting off a water surface is very low for incidence angles in a broad range about Brewster's angle $\left(53^{\circ}\right)$. If the instrument is oriented such that it only accepts the vertically polarized component for a given sounding then the measurement SNR is expected to be very low in clear-sky or nearly clear-sky scenes, making the retrieval of $\mathrm{XCO}_{2}$ unreliable. The polarization angle of any particular sounding is a quantity that is calculable from the observing geometry and sensor orientation. The local meridian plane, formed by the local normal and the ray from the ground FOV to the satellite, forms the reference plane for polarization. The polarization angle of a measurement $\left(\phi_{\mathrm{p}}\right)$ is then defined as the angle between the axis of the instrument's accepted polarization and this reference plane (Bösch et al., 2015). Since fundamental physics predicts that scattered light will be preferentially polarized parallel to the plane of a horizontal surface, i.e., perpendicular to the local meridian reference plane, the closer the OCO-3 polarization angle to $90^{\circ}\left(0^{\circ}\right)$, the more (less) reflected sunlight incident on the instrument will pass through

\footnotetext{
${ }^{1}$ As noted in Crisp et al. (2017), the OCO-2 instrument was built erroneously; it was intended to be sensitive only to light parallel to the long axis of the spectrometer slits. OCO-3 was built in the same manner. This error was mitigated on OCO-2 by yawing the spacecraft in order to maximize the signal over ocean while simultaneously maintaining sufficient electrical power generated from sunlight incident on the spacecraft solar panels. For OCO-3, electrical power comes from the ISS and is therefore a nonissue.
}

to the detectors, assuming a constant amount of polarization of the light.

The polarized intensity detected by OCO- 2 or OCO-3 is given by

$I_{\text {meas }}=m_{\mathrm{I}} I+m_{Q} Q+m_{U} U$,

where $I$ represents the total intensity, and $Q$ and $U$ represent components of the linearly polarized portion of the light. The circular component of polarization, $V$, is ignored as it is typically extremely close to zero in the atmosphere, and most instruments are designed to be insensitive to it. The so-called Stokes coefficients $m_{i}$ for an instrument containing a polarizer such as OCO-2 and OCO-3 are given by

$m_{\mathrm{I}}=\frac{1}{2}$,
$m_{Q}=\frac{1}{2} \cdot \cos \left(2 \phi_{\mathrm{p}}\right)$,
$m_{U}=\frac{1}{2} \cdot \sin \left(2 \phi_{\mathrm{p}}\right)$.

A critical difference in OCO-3 observations aboard the ISS is that the polarization angle of the measurements will not be constant or tied to latitude, as is the case for OCO-2, whereby $\phi_{\mathrm{p}}$ is controlled by the dynamic orientation of the spacecraft to maximize instrument throughput (Crisp et al., 2017). For OCO-2 all data since November 2015 have been collected with the spacecraft yawed at $30^{\circ}$, a nearly constant polarization angle. For OCO-3, the polarization angle of the glint measurements will vary significantly in space and time as the PMA is oriented to view the ground target of interest. 
Detailed optical modeling and laboratory tests were performed to simulate the effects of the PMA-induced changes to the polarization angle. The analysis shows that $\phi_{\mathrm{p}}$ is largely driven by the PMA elevation angle with some influence from the PMA azimuth angle. For elevation angles below $20^{\circ}$, the polarization angle is nearly equal to the elevation angle of the PMA. In the nadir-observing mode, the sensitivity to polarization is essentially negligible. However, for all off-nadir measurements, i.e., glint, transition, target, and SAM modes, there will be a range of polarization angles as the elevation angle of the PMA is adjusted to view the ground target.

These effects are neatly summarized in Fig. 6, which shows contours of the theoretical $\mathrm{O}_{2}$ A-band SNR as a function of both solar zenith angle (SZA) and polarization angle for a specularly reflecting surface model (Cox and Munk, 1954) at a fixed wind speed of $8 \mathrm{~m} \mathrm{~s}^{-1}$. The constant polarization angle of OCO- 2 at $30^{\circ}$ is designated by the horizontal dot-dashed line, while the polarization angle of OCO-3 assumed in this work is shown by the labeled dashed line, which used a simple but inexact parameterization of the relationship between the PMA elevation angle ( $\zeta_{\text {PMA }}$ ) and the polarization angle. In the figure, the actual range of polarization angles for OCO-3 expected on-orbit using a more complete parameterization is indicated by the gray shaded area. As stated above, this range is closely tied to the PMA elevation angle, which itself is closely related to the solar zenith angle at the glint spot. Note that actual on-orbit OCO-3 SNRs over ocean at the higher SZA values will be somewhat less than those depicted in Fig. 6 and Sect. 5, as OCO-3 will offpoint from the true glint spot to avoid saturating its detectors, as was done for OCO-2 (Crisp et al., 2017).

\subsection{Simulated meteorology, gas and cloud-aerosol fields}

In our simulations, the vertical profiles of standard meteorological information needed to calculate realistic radiances were taken from the National Centers for Environmental Prediction (NCEP) (Saha et al., 2014). The NCEP database has a native spatial resolution of $2.5^{\circ}$ latitude by $2.5^{\circ}$ longitude (10 512 spatial points) with variables given on 17 vertical layers every $6 \mathrm{~h}$. For this work, the model was sampled at individual OCO-3 observations, defined by time, latitude, longitude, and surface elevation for temperature, humidity, $2 \mathrm{~m}$ temperature, surface pressure, and winds. The data are interpolated spatially and temporally to 26 vertical levels to create "scenes" for every individual OCO-3 sounding.

Vertical values of carbon dioxide for each sounding were sampled from the CarbonTracker 2015 database (CT2015) (Peters et al., 2007, with updates documented at http:// carbontracker.noaa.gov (last access: April 2019), which has a native spatial resolution of $2.0^{\circ}$ latitude by $3.0^{\circ}$ longitude (10800 spatial points), with $\mathrm{CO}_{2}$ mole fractions given on 25 vertical layers every $3 \mathrm{~h}$. Data are interpolated in space

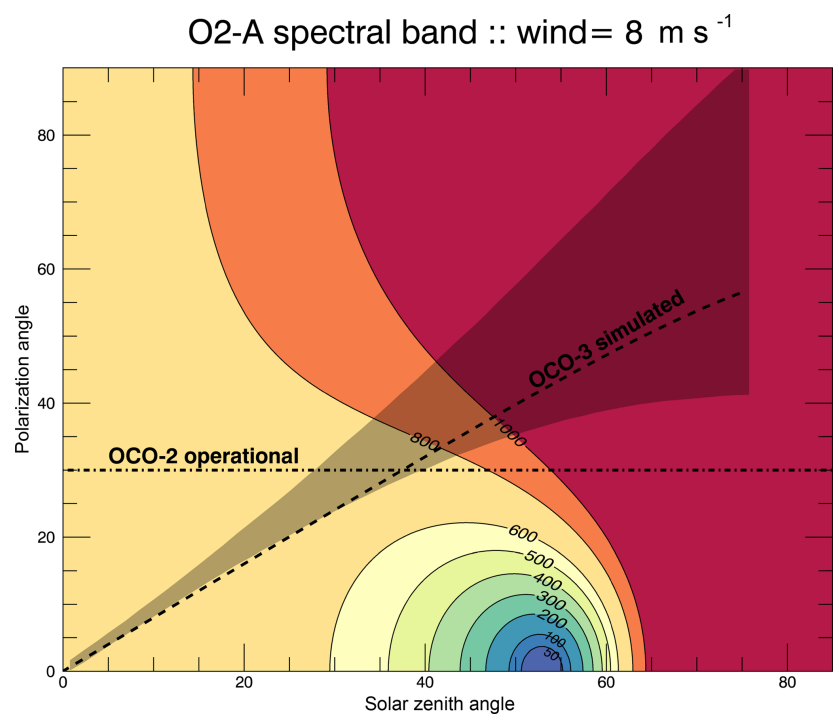

Figure 6. Contour plot of the theoretical SNR versus solar zenith and polarization angles as determined from a Cox and Munk surface reflectance model. Results here are for the $\mathrm{O}_{2} \mathrm{~A}$ band assuming an $8 \mathrm{~m} \mathrm{~s}^{-1}$ surface wind speed. Results for the $\mathrm{CO}_{2}$ spectral bands and for other realistic wind speeds look qualitatively similar (not shown). The fixed OCO-2 operational polarization angle due to the $30^{\circ}$ instrument yaw is indicated by the horizontal dot-dashed line, while the simple relationship between the OCO-3 polarization angle and solar zenith angle used in these simulations is indicated by the dashed line. The gray shaded region shows the range of the expected on-orbit OCO-3 polarization angles determined from recent calculations.

and time to match individual OCO-3 soundings. Note that although the ISS ephemeris was taken from 2015, the CT database was sampled for 2012. Ultimately this makes no difference to the overall outcomes reported in this paper (which are not focused on actual carbon cycle science), but it is important to note that the simulations are representative of an Earth-like system, not the actual conditions on Earth at the time of the soundings.

For each individual sounding, a cloud and aerosol profile containing 25 vertical layers was built based on a random selection from a monthly climatology of CALIOP profiles based on the 05kmALay product (Winker et al., 2007) as described in the OCO simulator document (O'Brien et al., 2009). This is a static database of real CALIPSO profiles measured in a single year binned at $2.0^{\circ}$ latitude by $2.0^{\circ}$ longitude (16200 spatial points), with each bin containing on average about 90 profiles for a total of approximately 1.4 million profiles. While these profiles do not capture the diurnal characteristics of cloud and aerosol fields since CALIOP has a fixed local overpass time, they are sufficient for this analysis, which assesses statistics on monthly or seasonal timescales. 


\subsection{Simulated land surface model and SIF}

A model of the Earth's surface is a critical component for the calculation of reflected solar radiances. For land surfaces, scalar bidirectional reflectance distribution functions (BRDFs) were taken from the MODIS $16 \mathrm{~d}$ MCD43B1 product (Schaaf et al., 2002). For water surfaces, a fully polarized Cox and Munk model with a foam component based on wind speed was used. Additional details and citations can be found in the simulator Algorithm Theoretical Basis Document (ATBD) (O'Brien et al., 2009). Realistic estimates of solar-induced chlorophyll fluorescence from biological activity were added to the $\mathrm{O}_{2} \mathrm{~A}$-band $\mathrm{L} 1 \mathrm{~b}$ radiances based on the implementation of Frankenberg et al. (2012). A static gross primary production (GPP) climatology of Beer et al. (2010), which is a mean monthly climatology based on the 18 International Geosphere-Biosphere Programme (IGBP) (Loveland and Belward, 1997) surface types at $0.5^{\circ}$ by $0.5^{\circ}$ latitude and longitude resolution, is scaled to a daily average SIF value using the empirical scaling factor of Frankenberg et al. (2011). Daily average SIF is converted to instantaneous SIF via scaling by the instantaneous solar insolation relative to the average for that day and location. The wavelength dependence is a double Gaussian function as given in Frankenberg et al. (2012). Overall, this provides values of SIF that are representative in time (seasonal and diurnal cycle) and space (as a function of latitude and local plant physiology). It is worth noting that the use of the static GPP climatology does not allow for interannual variability, but this has no effect on the single year of simulated data presented here.

\subsection{Simulated L1b radiances}

Radiances, as are expected to be observed by the OCO-3 instrument in space, are calculated using the same forward model (FM) that has previously been employed for GOSAT and OCO-2 simulation studies; e.g., O'Dell et al. (2012). The FM consists of an atmospheric model, surface model, instrument model, solar model, and radiative transfer model.

The solar spectrum is comprised of two parts: a pseudotransmittance spectrum (Toon et al., 1999) and a solar continuum spectrum (Thuillier et al., 2003) used to produce a high-resolution, absolutely calibrated input solar spectrum for the forward model (Bösch et al., 2015). For this work, the gas absorption coefficients, i.e., spectroscopy, of the OCO-2 operational B8 L2FP algorithm, ABSCO v5.0.0, were used. The instrument model, which includes the instrument line shapes (ILSs), radiometric characteristics, polarization sensitivity, and noise specifications, was taken from the OCO-3 thermal vacuum tests performed in September 2016. Noise was applied to the calculated radiances via the same model used for OCO-2, as described in Rosenberg et al. (2017). The radiative transfer calculation accounts for multiple scattering from clouds and aerosols as well as polarization, as described in O'Brien et al. (2009) and references therein.

\section{Level 2 preprocessors and full physics retrieval algorithm}

The primary data products for OCO-2 and OCO-3 are the column-averaged dry-air mole fraction of $\mathrm{CO}_{2}\left(\mathrm{XCO}_{2}\right)$ and the solar-induced chlorophyll fluorescence, both of which can be used to help constrain the global carbon cycle; e.g., Eldering et al. (2017b) and Sun et al. (2017). For this work, the simulated $\mathrm{L} 1 \mathrm{~b}$ radiances were analyzed with the same tools used in OCO-2 operational data processing, as described in Sect. 4 of Eldering et al. (2017a). These steps include prescreening, the level 2 full physics (L2FP) algorithm, quality filtering, and the application of a bias correction (BC) for $\mathrm{XCO}_{2}$. This section briefly discusses each of the components as it relates specifically to the OCO-3 simulations. Relevant citations containing the full details are provided.

\subsection{Preprocessors}

Cloud screening was performed using only the A-band preprocessor (ABP), as described in Taylor et al. (2016). The ABP identifies cloud-contaminated soundings primarily via a threshold on the difference in retrieved and prior surface pressure in the oxygen A band, typically $\pm 25 \mathrm{hPa}$. Although operational OCO-2 data also utilize a weak filter on the ratio of $\mathrm{CO}_{2}$ retrieved independently in the strong and weak $\mathrm{CO}_{2}$ bands by the IMAP-DOAS preprocessor (IDP), we did not implement this filter for cloud screening. The IDP $\mathrm{CO}_{2}$ and $\mathrm{H}_{2} \mathrm{O}$ ratios were, however, used for post-L2FP retrieval quality filtering and bias correction. In addition, IDP performs a retrieval of SIF, which is used as a prior for the full physics L2FP SIF retrieval that is included in the L2FP state vector as a necessary interferent parameter (see Sect. 3.5 of O'Dell et al., 2018). Both preprocessors neglect scattering in the atmosphere (except Rayleigh scattering is included in ABP), making them computationally very efficient.

\subsection{Full physics retrieval algorithm for $\mathrm{XCO}_{2}$}

The soundings that were identified as clear by the ABP cloud flag were then run through the OCO-2 B8 operational L2FP retrieval algorithm. The algorithm was first described in Bösch et al. (2006) and Connor et al. (2008) prior to the failed launch of OCO-1 in February 2009, and it was later applied to GOSAT as described in O'Dell et al. (2012). Recent updates and a complete description of the modern B8 version of the algorithm can be found in Bösch et al. (2015) and O'Dell et al. (2018).

In summary, the L2FP is an optimal estimation retrieval containing a prior that maximizes the a posterior probability of the solution space via minimization of the radiance residuals through the chi-squared statistic. The solution is solved on 20 vertical levels, with the state vector containing $\mathrm{CO}_{2}$ dryair mole fraction, aerosol parameters, surface albedo, wind speed, water vapor, a temperature scaling factor, and a SIF 
term. The high-spectral-resolution measurements of top-ofatmosphere reflected radiances measured by sensors such as GOSAT, OCO-2, or OCO-3 serve as the primary source of information in the retrieval. The measurements are coupled with an a priori state of the atmosphere (the state-vector elements listed above) in order to constrain the inversion. Within the L2FP retrieval, modeled spectra are generated by a radiative transfer (RT) code as described in O'Dell et al. (2012) and Bösch et al. (2015). Although they share many components, the L2FP RT code base differs slightly from the RT model used to generate the simulated $\mathrm{L} 1 \mathrm{~b}$ radiances, thus creating a realistic error source in the simulation exercise.

\subsection{Filtering and bias correction approach}

The NASA operational procedure for both OCO-2 and GOSAT applies a quality filtering and bias correction (BC) process to the $\mathrm{L}_{2} \mathrm{FP} \mathrm{XCO}_{2}$ (O'Dell et al., 2018). Correlations between variables and $\mathrm{XCO}_{2}$ error variability are quantified and used to develop the filtering thresholds and linear bias correction equations. The quality filtering is designed to remove soundings with anomalous $\mathrm{XCO}_{2}$ values relative to other soundings in close proximity, making use of the assumption that real variations in $\mathrm{XCO}_{2}$ are quite small $(<1 \mathrm{ppm})$ on small scales $(<100 \mathrm{~km})$. Some form of "truth" metric, or truth proxy, is required with which to calculate an "error" in $\mathrm{XCO}_{2}$. For operational OCO-2 data, several forms of a truth proxy are used, as detailed in Sect. 4.1 of O'Dell et al. (2018).

A similar treatment was applied to the OCO-3 simulation dataset. However, with simulations it was possible to use the actual true $\mathrm{XCO}_{2}$ as the truth proxy in the QF and $\mathrm{BC}$ procedures. There are both advantages and disadvantages to the circularity imposed by knowing the true values of the atmospheric state. In this case, we expect that the use of the truth data will result in an overly optimistic QF and BC. On the other hand, we do not have to consider errors in the truth proxy itself in our analysis, an issue of real concern when working with real measurements such as those from TCCON validation sites or model estimates of $\mathrm{XCO}_{2}$.

At its completion, the quality filtering and bias correction procedure assigns to every sounding a binary flag indicating good (0) or bad (1) quality, as well as a $\mathrm{BC}$ value in units ppm. The operational OCO-2 BC equation contains three components: a correction based on retrieval variables (parametric), a correction for inter-footprint dependence, and a global bias, each calculated separately for land (combined nadir and glint) and ocean-glint. For the OCO-3 simulations the inter-footprint bias is not needed since only a single footprint per frame was calculated. Explicit results from the procedure as performed on the OCO-3 simulations are given in Sect. 5.3 and 5.4 .

\section{Results}

This section discusses characteristics of the L1b radiances, performance of the preprocessors, and application of the quality filtering and bias correction methodology before presenting the $\mathrm{L} 2 \mathrm{FP} \mathrm{XCO}_{2}$ results. In addition, we provide a brief analysis of the SIF determined by the IMAP-DOAS preprocessor retrieval. Table 1 summarizes the number of soundings in the simulated dataset at each stage of the analysis, broken down by nadir-land and glint-water observations.

\subsection{Simulated L1b radiance characteristics}

At a gross level, the characteristics of the simulated OCO-3 radiances are very similar to those from real OCO-2 measurements. The high-resolution spectra for OCO-3 (not shown) exhibit the expected absorption features that allow for cloud and aerosol screening and the retrieval of surface pressure and SIF (from the $\mathrm{O}_{2} \mathrm{~A}$ band) and $\mathrm{XCO}_{2}$ (from the weak and strong $\mathrm{CO}_{2}$ bands).

However, some differences are expected between the two sensors in both measured signal and instrument noise due to the addition of the PMA and calibration characteristics of the spectrometers, e.g., dark noise, stray light, and ILS. Optical inefficiencies in the OCO-3 PMA will reduce the transmission of light by about $17 \%$ in the $\mathrm{O}_{2} \mathrm{~A}$ band and $7 \%$ and $5 \%$ in the weak and strong $\mathrm{CO}_{2}$ bands, respectively. To compensate for the effects of the PMA, the instrument aperture of the $\mathrm{O}_{2} \mathrm{~A}$ band was increased. When all of the optical elements and instrument changes are considered, the $\mathrm{O}_{2} \mathrm{~A}$ band transmission of OCO-3 will be about $95 \%$ of OCO-2, while the weak and strong $\mathrm{CO}_{2}$ bands will have $75 \%$ of the transmission of OCO-2, thus reducing the observed signal for the same scene.

The instrument calibration parameters for the OCO-3 simulations reported here were derived from the September 2016 prelaunch thermal vacuum testing (TVAC), which was performed using an early version of the instrument telescope and without the PMA installed. The noise coefficients were adjusted post hoc to account for the reduced optical throughput caused by the PMA, which was discussed in Sect. 2.2. Although the final thermal vacuum test of the OCO-3 payload, including the PMA, was completed in July 2018, analysis is still in progress to generate calibration coefficients from these data. Some values will remain fixed, while others will be regularly updated in-flight. Instrument performance will be reported in forthcoming papers postlaunch. Based on preliminary analysis, the updated instrument characteristics are not expected to change at a level that would greatly effect the results presented here.

A key characteristic of the radiances measured by satellite sensors is the SNR, which effectively determines the information content of the measurements, thereby controlling the precision of the retrieval estimates of $\mathrm{XCO}_{2}$ and SIF. The signal for each band is calculated from continuum-level radi- 
Table 1. Summary statistics of the filtering for each stage of the analysis. Results are shown for the nadir-land, glint-water, and combined soundings separately.

\begin{tabular}{|c|c|c|c|c|c|c|c|c|}
\hline \multirow[t]{2}{*}{ Filter } & \multirow[t]{2}{*}{$\begin{array}{r}N \\
\text { Combined }\end{array}$} & \multirow[t]{2}{*}{$\begin{array}{r}N \\
\text { Land }\end{array}$} & \multirow[t]{2}{*}{$\begin{array}{r}N \\
\text { Water }\end{array}$} & \multicolumn{3}{|c|}{$\begin{array}{l}\text { Fraction passing } \\
\text { (relative to combined total) }\end{array}$} & \multicolumn{2}{|c|}{$\begin{array}{c}\text { Fraction passing } \\
\text { (relative to surface type total) }\end{array}$} \\
\hline & & & & Combined & Land & Water & Land & Water \\
\hline L1b (all) & 982922 & 337211 & 645711 & $100.0 \%$ & $34.3 \%$ & $65.7 \%$ & $100.0 \%$ & $100.0 \%$ \\
\hline $\mathrm{ABP}$ (pass) & 237736 & 107295 & 130441 & $24.2 \%$ & $10.9 \%$ & $13.3 \%$ & $31.8 \%$ & $20.2 \%$ \\
\hline L2FP (converge) & 196211 & 96182 & 100029 & $20.0 \%$ & $9.8 \%$ & $10.2 \%$ & $28.5 \%$ & $15.5 \%$ \\
\hline QF (good) & 140741 & 68264 & 72477 & $14.3 \%$ & $6.9 \%$ & $7.4 \%$ & $20.2 \%$ & $11.2 \%$ \\
\hline
\end{tabular}

ances using the 10 channels with the highest values, after filtering for outliers that occasionally exist due to cosmic rays or some other random electronic anomaly. The OCO noise model combines contributions from a constant background (dark noise) term and a photon (shot noise) term, the latter of which is proportional to the square root of the radiance (Rosenberg et al., 2017).

Figure 7 compares the OCO-2 SNR calculated from the operational noise model (solid traces) against OCO-3 (dashed traces) versus a measure of the surface brightness, parameterized as the albedo scaled by the cosine of the solar zenith angle: $A \cdot \cos (\mathrm{SZA})$. Panel (a) displays the SNR of each spectral band for both sensors, while panel (b) shows the ratio of the two sensors' SNR per spectral band. These data demonstrate that the only situation in which OCO-3 has a higher SNR than OCO-2 is in the $\mathrm{O}_{2} \mathrm{~A}$ band when $A \cdot \cos (\mathrm{SZA}) \gtrsim 0.15$. This typically occurs over very bright deserts and during glint-water measurements when the sun is low in the sky. It is worth noting that the $\mathrm{O}_{2} \mathrm{~A}$ band is used primarily for cloud and aerosol detection and for the L2FP surface pressure retrieval as well as for SIF. In both the weak and strong $\mathrm{CO}_{2}$ bands (green and red, respectively, in Fig. 7), OCO-3 always has a significantly lower SNR than OCO-2. This reduced SNR can be attributed to some combination of increased noise in the instrument detectors and/or to a decreased signal incurred by the use of the PMA, a polarizer in the telescope, and a larger center obscuration in the entrance optics.

The overall SNR differences are captured in the histograms of Fig. 8, which compare the OCO-3 simulations with the real SNR for operational OCO-2 B8 measurements acquired in 2016. The operational OCO-2 data have been down-selected to include only a single footprint per frame and one sounding every $10 \mathrm{~s}$ to provide a fairer comparison against the OCO-3 simulations. Both datasets have been screened using their respective L2FP quality flags, which were introduced in Sect. 4.3 and will be discussed in more detail in Sect. 5.3. At a gross level, the data look reasonably similar, although a few key distinctions stand out, particularly the fact that the slightly brighter OCO-3 $\mathrm{O}_{2} \mathrm{~A}$ band is primarily due to a long tail of high values for glint-water soundings. The OCO-3 weak $\mathrm{CO}_{2}$ band exhibits a substan- tially lower SNR for glint-water compared to OCO-2, while the strong $\mathrm{CO}_{2}$ band tends to be somewhat lower than OCO2. These figures show that the OCO-3 data will include fewer data with SNR values over 600 and more data with SNR between 200 and 400. Previous OCO-2 studies and experience with the real data show that an SNR of 200 is sufficient to achieve the desired precision of the retrieval algorithm. As will be shown in Sect. 5.5 and 5.6, the L2FP retrieval still provides good estimates of $\mathrm{XCO}_{2}$ and SIF on this set of OCO-3 simulated radiances, even with the lower SNR values.

Maps comparing the simulated OCO-3 SNR to the operational B8 OCO-2 data are shown in Fig. 9 for the month of April for each spectral band. Qualitatively, the overall patterns agree quite well, although the difference in latitudinal coverage from the two spacecraft is apparent as are differences in the throughput, notably over the Amazon, the Sahara, and eastern China. A higher fraction of the soundings that converge in the L2FP retrieval are assigned a good quality flag in the OCO-3 simulations (approximately $70 \%$ versus only about $40 \%$ for real OCO-2 B 8 data). The differences in throughput are likely driven by deficiencies in the simulation setup. In particular, there is a lack of a southern Atlantic anomaly model and a parameterized cloud and aerosol scheme in the L1b simulations with full realism. We expect that real on-orbit OCO-3 good quality sounding fractions will in reality be closer to the OCO-2 values, especially over the three continental areas mentioned above. For both sensors, the highest SNRs are obtained over unvegetated (bright) land and for glint-water when the sun is low in the sky, which produces a strong specular reflection. The lowest values of SNR occur when the sun is high in the sky and for vegetated (dark) land surfaces at higher latitudes. As with OCO-2, the weak $\mathrm{CO}_{2}$ band displays the highest SNR values, while the $\mathrm{O}_{2} \mathrm{~A}$ band and strong $\mathrm{CO}_{2}$ bands have lower but comparable SNRs.

A final glimpse of the SNR characteristics is shown in Figs. 10 and 11, which compare the SNR dependence on latitude and SZA for both sensors. The restriction of OCO3 to latitudes below $\sim 54^{\circ}$ is pronounced, especially for the glint-water soundings, when comparing to the wider latitudinal distribution obtained from OCO-2. This is simply a con- 

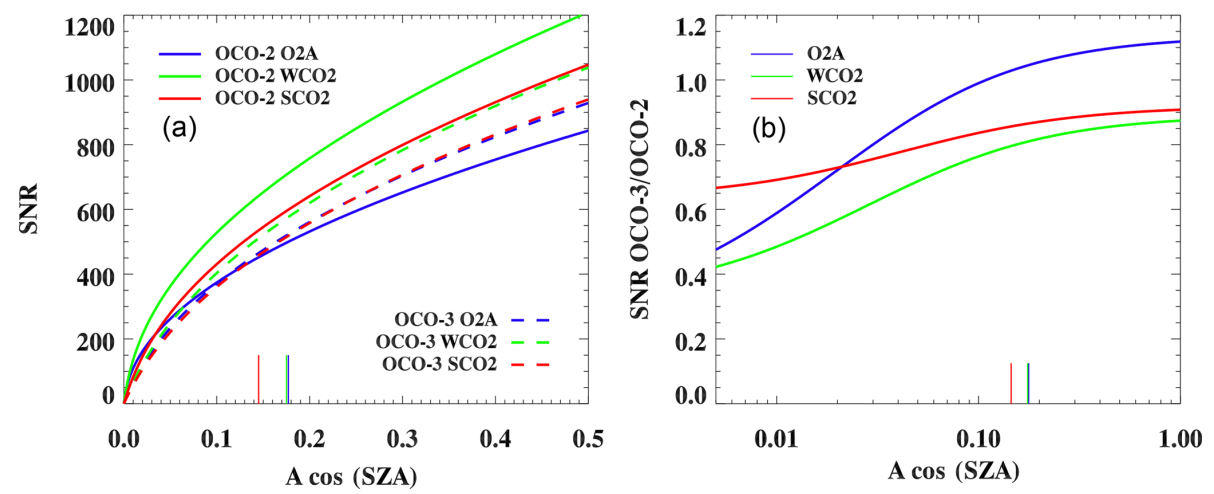

Figure 7. OCO-2 and OCO-3 mean SNR (averaged across footprints and channels) for each band as a function of the product of surface albedo and cosine of solar zenith angle (a). The quantity A $\cos (\mathrm{SZA})$ is proportional to the reflected sunlight off a surface. Panel (b) shows the ratio of OCO-3 SNR to OCO-2 SNR using a logarithmic abscissa scale. The small vertical lines represent A cos(SZA) for Railroad Valley at the winter solstice. OCO-3 SNR is lower at lower signal levels because it has a higher noise floor than OCO-2.

(a)

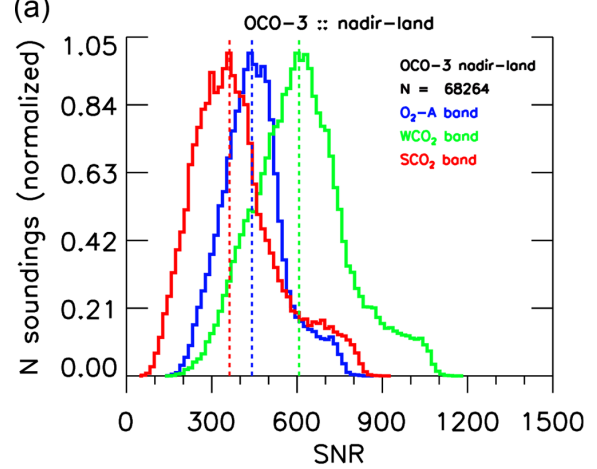

(c)

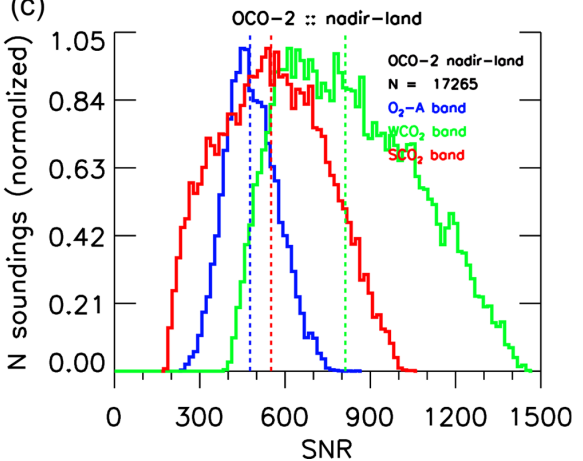

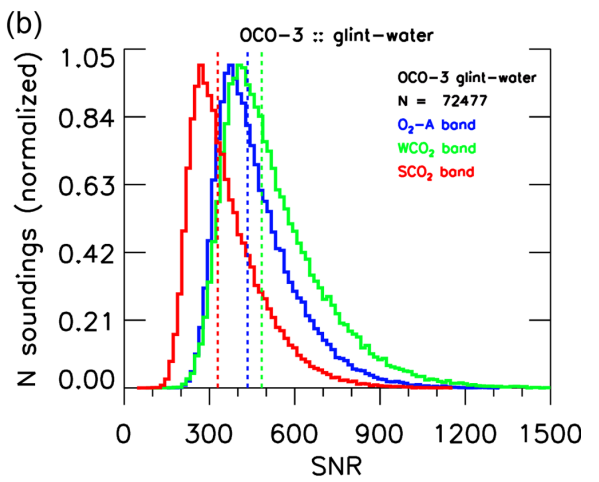

(d)

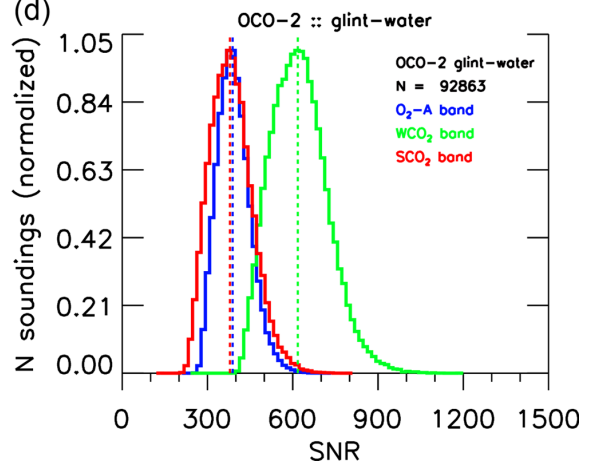

Figure 8. SNR histograms comparing simulated OCO-3 (a, b) to operational B8 OCO-2 (c, d) for nadir-land (a, c) and glint-water (b, d). The colors represent the three spectral bands, as described in the legend. Both datasets have been filtered using their respective L2FP quality flags. The median value for each spectral band is shown as a vertical dashed line in the corresponding color.

sequence of the ISS precessing orbit versus the polar orbit of OCO-2. It is also evident that the OCO-3 measurements span a much larger SZA range $\left(\sim 75\right.$ to $\left.0^{\circ}\right)$ compared to OCO-2. As was demonstrated previously in the histogram plots (Fig. 8), we find that for nadir-land the SNR values tend to be lower for OCO-3 compared to OCO-2 in all spectral bands, with the exception of a few high $\mathrm{O}_{2}$ A-band SNRs around $20^{\circ}$ latitude that correspond to the Sahara. For glintwater soundings, there is a population of very high SNR val- ues $(>800)$ spanning the full latitudinal space at SZA $\sim 60^{\circ}$ due to the very bright specular glint spot achieved under these conditions.

While real on-orbit SNR characteristics will likely differ somewhat from those shown here, these simulations suggest that the instrument has been well built and well calibrated and should provide an SNR that meets the mission requirements. In addition, due to the nature of the precessing orbit of the ISS, which decouples the solar zenith angle from the lat- 
SNR :: OCO-3 :: month_04_QFgood :: $\mathrm{O}_{2}-\mathrm{A}$ band

(a)

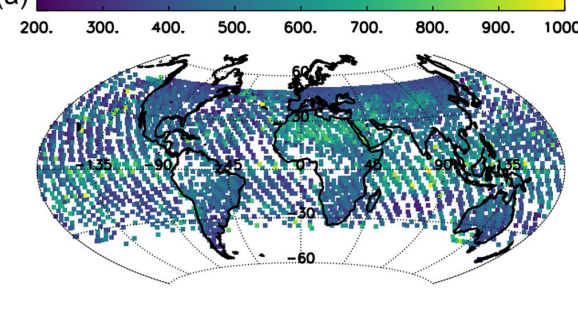

NumSound $=11978$

SNR :: OCO-3 :: month_04_QFgood :: $\mathrm{WCO}_{2}$ band

(c)

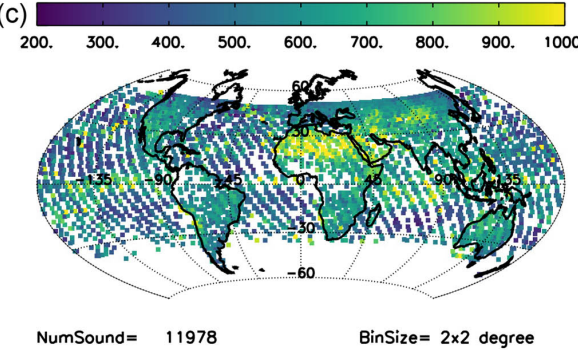

SNR :: OCO-3 :: month_04_QFgood :: $\mathrm{SCO}_{2}$ bond

(e)
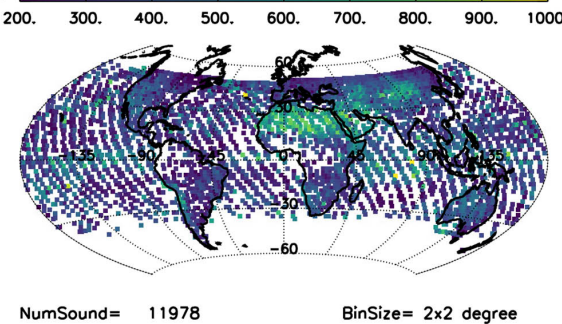

SNR :: OCO-2 :: month_04_QFgood :: $\mathrm{O}_{2}-\mathrm{A}$ band

(b)

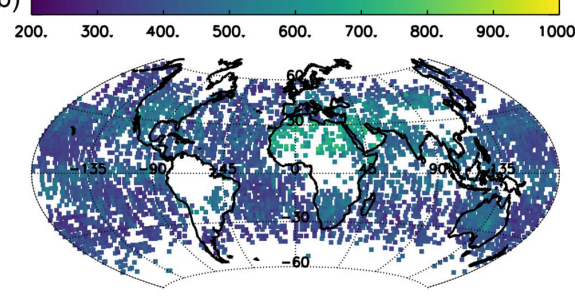

NumSound $=8661$

SNR :: OCO-2 :: month_04_QFgood :: $\mathrm{WCO}_{2}$ band

(d)
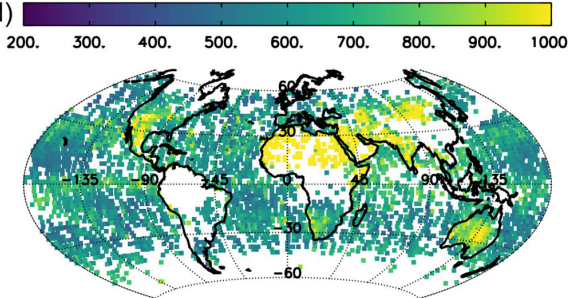

NumSound $=8661$

BinSize $=2 \times 2$ degree

SNR :: OCO-2 :: month_04_QFgood :: $\mathrm{SCO}_{2}$ band

(f)
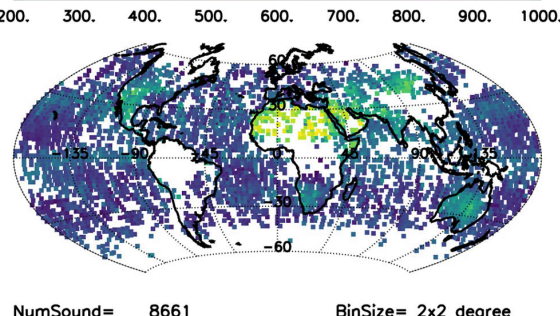

Figure 9. Maps comparing the SNR of OCO-3 (a, c, e) to OCO-2 (b, d, f) for each spectral band (rows) for the month of April binned in $2^{\circ}$ latitude bins. Both datasets have been filtered using the L2FP quality flag. The operational OCO-2 data have been down-selected to include a single footprint and one sounding every $10 \mathrm{~s}$ to provide a fairer comparison against the OCO-3 simulations. The OCO-2 data also include both nadir and glint land soundings in addition to glint-water.

itude, we expect that the SNR distribution, which fundamentally drives the information content in the L2FP retrievals, will not be tied to latitude in the same way that it is for OCO2. This has implications as to the spatial patterns of good quality $\mathrm{XCO}_{2}$ and SIF retrievals, as will be discussed in the following sections.

\subsection{Preprocessor performance}

For this simulation experiment only the ABP cloud flag was used to select soundings, although real operational sounding selection is expected to be slightly more elaborate (see Sect. 2 of O'Dell et al., 2018). In particular, no IDP variables were used in the L2FP sounding selection here, although they were used later in the post-filtering and bias correction. The results shown in Table 1 indicate that about a quarter $(24.2 \%)$ of all of the observations passed the ABP cloud flag, leaving about 250000 to run through the L2FP retrieval. By viewing mode, approximately one-third $(31.8 \%)$ of the nadir-land and one-fifth $(20.2 \%)$ of the glint-water observations passed the ABP cloud flag. These statistics are roughly similar to those seen in real OCO-2 operational processing.

Figure 12 shows maps of the clear-sky fractions in each $2^{\circ}$ spatial bin (left) and the resulting clear-sky sounding densities (right). As expected, the highest fraction (up to about $75 \%$ ) of the scenes pass in the arid land regions, where there are few clouds and aerosols. The southern subtropical oceans also tend to have areas of moderately high passing rates of $\sim 50 \%$. Tropical land regions, e.g., the Amazon, Congo, and Indonesian rainforests, have on average only about $5 \%$ to $10 \%$ passing rates. Most temperate land regions such as the eastern United States and southern Europe generally have passing rates of $\sim 30 \%$. These results meet expectations and 

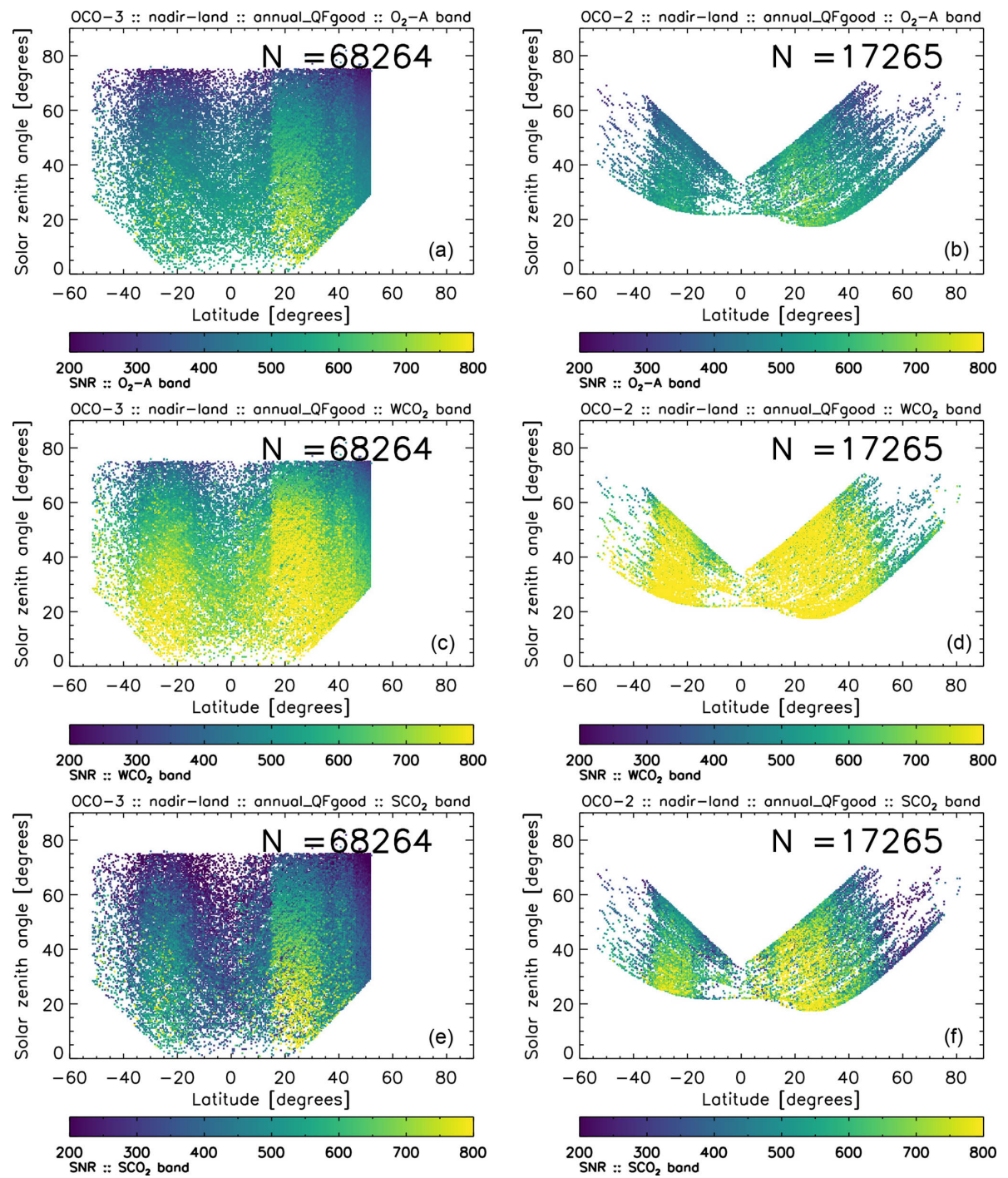

Figure 10. Comparison of the nadir-land SNR of OCO-3 (a, c, e) to OCO-2 (b, d, f) for each spectral band (rows) for the full annual dataset. Both datasets have been filtered using the L2FP quality flag. The operational OCO-2 data have been down-selected to include a single footprint and one sounding every $10 \mathrm{~s}$ to provide a fairer comparison against the OCO-3 simulations.

are qualitatively very similar to those seen in Fig. 1 of O'Dell et al. (2018) for OCO-2 operational B8 data.

Figure $12 \mathrm{~b}$ confirms that the highest density of cloud-free soundings (more than 100 per $2^{\circ}$ bin) is found over the arid regions of the globe, as expected. In addition, a large number of soundings are found over Northern Hemisphere land at the satellite orbit inflection points. Much of the temperate land regions contain $\sim 30-50$ soundings per bin, while few soundings remain over tropical forests. In glint-water viewing, the regions of high clear-sky fraction have $\sim 50$ to 80 soundings per $2^{\circ}$ bin, while the cloudy areas contain only $\sim 10$ soundings per bin selected for processing by the L2FP retrieval. Recall that on-orbit OCO-3 sounding densities will be approximately 240 times greater due to the reduced spatiotemporal sampling used in this simulation set.

\subsection{Application of $\mathrm{XCO}_{2}$ quality filtering}

The L2FP retrieval algorithm described in Sect. 4.2 was applied to the cloud-screened set of soundings, and then, as with operational OCO-2 data, a set of post-processing filters were implemented to determine the binary $\mathrm{XCO}_{2}$ quality flag (QF) for each sounding. Details of the methodology are documented in O'Dell et al. (2018). Here, the true $\mathrm{XCO}_{2}$ for each sounding was used as the truth metric to assess residual biases and errors. This provides perhaps an overly optimistic interpretation of the results and should be considered an upper limit on the actual performance expected from on-orbit OCO-3 measurements.

Explicit values of the QF thresholds determined for the OCO-3 simulations are presented in Tables 2 and 3. The QF 

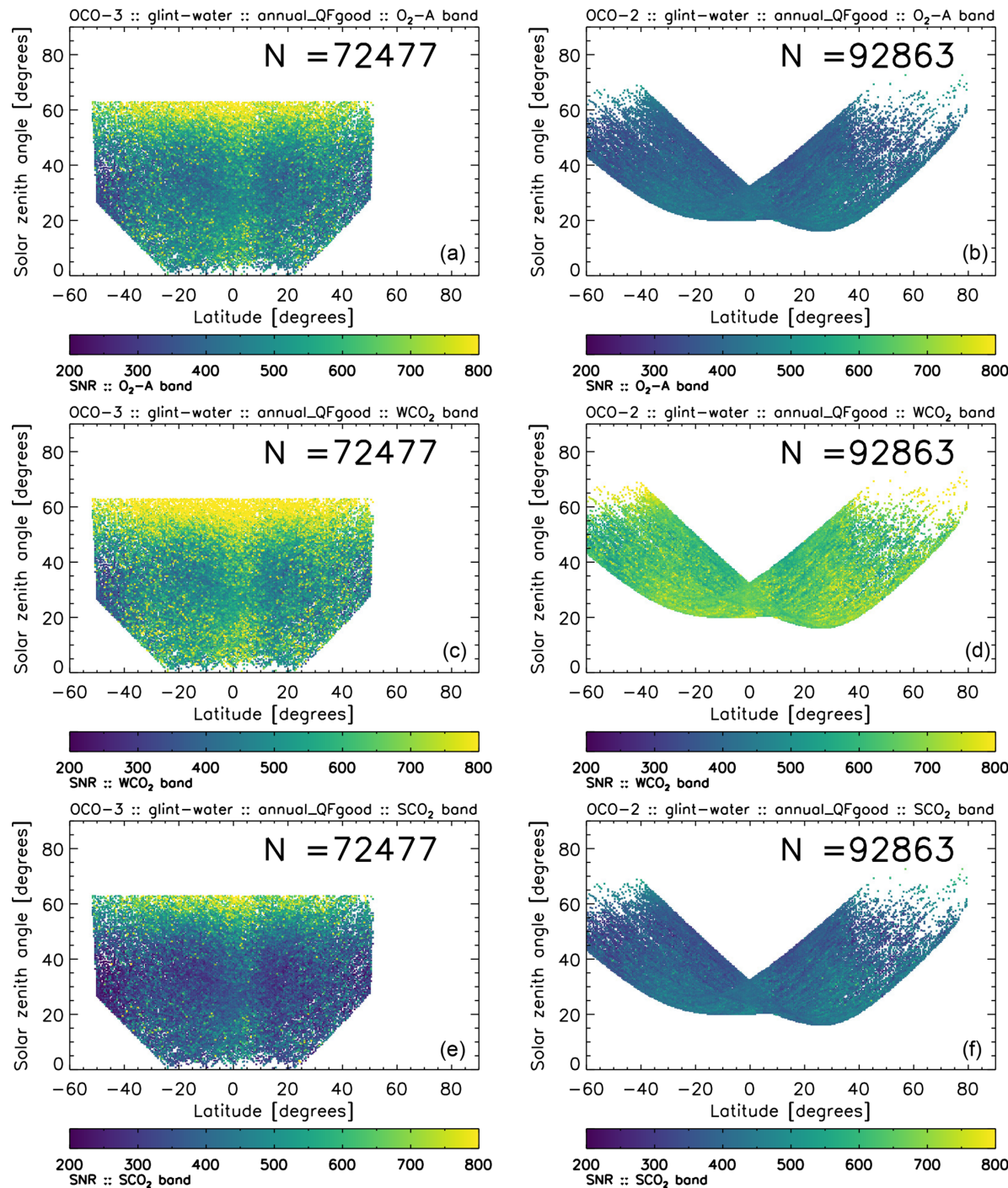

Figure 11. Same as Fig. 10, but for glint-water soundings.

(a)

Fraction of soundings possing ABP flog per bin

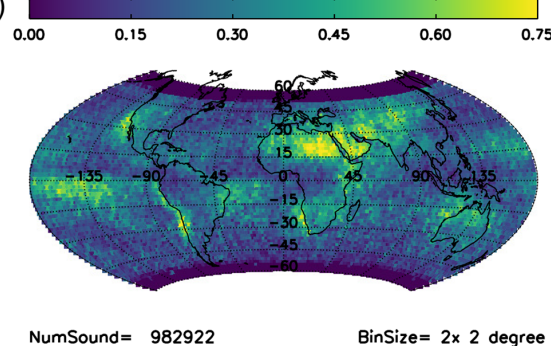

Number of soundings per bin

(b)

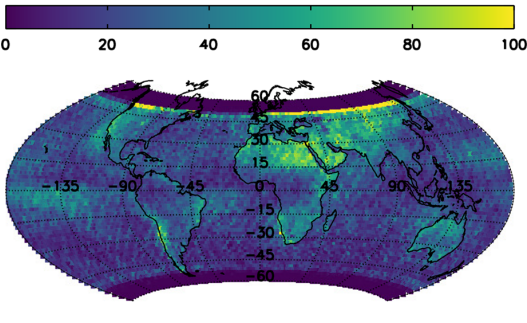

NumSound $=237736$

BinSize $=2 \times 2$ degree

Figure 12. Maps of the annual fraction of soundings passing the ABP cloud flag (a) and the resultant clear-sky sounding density (b) binned $2^{\circ} \times 2^{\circ}$ latitude. Number densities should be inflated by 240 to provide a real estimated number of soundings at the full spatiotemporal sampling. 
methodology was applied independently to the nadir-land and glint-water scenes, as is done with operational OCO-2 data. A total of 11 variables were used to form the QF for nadir-land, while 9 were used for glint-water. Not surprisingly, many of the same variables are selected for quality filtering the OCO-3 simulations as were used in the operational OCO-2 procedure (see, e.g., Figs. 10 and 11 of O'Dell et al., 2018). Approximately $70 \%$ of the soundings that converged in L2FP were assigned a good QF.

The quality filtering process had similar impacts on data volume across all months (not shown). On average, global data densities of good QF soundings in the simulations were 11000 to 12000 soundings per month or 33000 to 36000 per season. When using the full spatiotemporal resolution, this translates to approximately 2.5 million soundings per month (7.5 million per season), similar to the density of OCO-2 B8 data.

Figure 13 shows seasonal plots of the fraction (left column) and number (right column) of soundings assigned a good QF for each season (DJF, MAM, JJA, SON) binned in $4^{\circ}$ degree latitude-longitude bins. The spatial patterns are useful, but the absolute numbers need to be inflated by 240 to reflect actual predicted on-orbit throughput.

In general, the QF throughputs for glint-water are quite high $(>70 \%)$ in the tropics and subtropics $\left(<30^{\circ}\right.$ latitude) and display little seasonal cycle. The QF throughput is persistently low for glint-water observations at the turnaround latitude in the winter hemisphere. The QF throughputs are more varied for nadir-land observations, and a modest seasonal cycle is seen for some regions. But overall, the results look qualitatively similar to those from OCO-2 for the B8 operational dataset and demonstrate that the methodology is a robust procedure.

\subsection{Bias correction of $\mathrm{XCO}_{2}$}

The final bias correction (BC) for the OCO-3 simulations incorporates four of the QF variables for nadir-land and three for glint-water as shown in Table 4. Figure 14 illustrates how the final $\mathrm{BC}$ parameters for land affect the $\mathrm{XCO}_{2}$ error. Each panel shows median binned values of the $\mathrm{XCO}_{2}$ error (retrieved minus true in $\mathrm{ppm}$ ) versus a particular retrieval variable (heavy, black dots). Also shown are the range in $\mathrm{XCO}_{2}$ error (thin vertical bars) and the least-squares linear fit (thin dashed line). To provide context, the relative histogram of points is shown in the background by the shaded gray region. The slope of the fit, the standard deviation of the $\mathrm{XCO}_{2}$ error post-BC, and the percent of the variance explained by this variable are given in the legend. The original standard deviation is shown in the upper left panel for reference.

For land, $25 \%$ of the variance is explained by the difference in the L2FP-retrieved surface pressure from the prior (denoted dp), while another $15 \%$ is explained by the square root of the combined retrieved aerosol optical depth (AOD) from dust, water cloud, and sea salt (DWS). An additional
$3 \%$ and $2 \%$ are explained by the L2FP fine-mode AOD and the water vapor scaling factor, respectively. We believe that a minor indexing bug found in the simulated meteorology is responsible for the reliance on water vapor. The final reduction in $\mathrm{XCO}_{2}$ error is shown in Table 5, which gives the standard deviations $(\sigma)$ in the retrieved $\mathrm{XCO}_{2}$ with and without $\mathrm{QF}$ and BC. For land, $\sigma$ was reduced from 1.88 to $0.85 \mathrm{ppm}$ after application of both $\mathrm{QF}$ and $\mathrm{BC}$.

Figure 15 is similar to Fig. 14, but for the glint-water scenes. Here, $18 \%$ of the variance in $\mathrm{XCO}_{2}$ error is explained by the IDP $\mathrm{CO}_{2}$ ratio, while another $16 \%$ is explained by the ABP dP. An additional $7 \%$ is explained by the L2FP dP. The need for two preprocessor variables in the glint-water bias correction hints that the prescreening for clouds may not have been stringent enough. Use of the IDP results for prescreening on real OCO-3 data may alter this outcome. As seen in Table 5, the $\mathrm{XCO}_{2} \sigma$ was reduced from 2.15 to $0.52 \mathrm{ppm}$ for glint-water soundings after application of both $\mathrm{QF}$ and BC. It is likely that the smaller QF-BC $\sigma$ for glint-water $(0.52 \mathrm{ppm})$ relative to nadir-land $(0.85 \mathrm{ppm})$ is driven by L2FP retrieval interference errors such as albedo and aerosols, which vary more over land, as concluded by Worden et al. (2017) in their study of OCO-2 B7 data.

There are notable similarities and differences in the selected variables when comparing between the OCO-3 simulations and either real OCO-2 data (Sect. 4.3.1 of O'Dell et al., 2018) or OCO-2 simulations (Kulawik et al., 2018). In all cases the L2FP dp is found to be the primary bias correction parameter for land and water soundings. Both the real OCO-2 data and the simulated OCO-3 land data rely on a form of the aerosol parameterization for bias correction (DWS for the former and DWS and fine-mode aerosols for the latter). This stands to reason as aerosols are highly variable over land and have been shown to be a strong source of interference error (Connor et al., 2016).

A key difference is that the $\mathrm{L} 2 \mathrm{FP}$ variable $\mathrm{CO}_{2}$ grad del $\left(\delta \nabla_{\mathrm{CO}_{2}}\right)$, a measure of the change in the retrieved vertical profile of $\mathrm{CO}_{2}$ relative to the prior (see Eq. 5 in O'Dell et al., 2018), does not show up as a strong bias correction parameter in the simulated OCO-3 dataset. Kulawik et al. (2018) discuss in detail the ties between $\delta \nabla_{\mathrm{CO}_{2}}$, the L2FP prior $\mathrm{CO}_{2}$, and the partitioning of $\mathrm{CO}_{2}$ in the upper and lower atmosphere in the retrieved state vector. At this time we have no real explanation as to why $\delta \nabla_{\mathrm{CO}_{2}}$ is not showing up as a bias correction term in the OCO-3 simulations. Analysis of on-orbit OCO-3 data, when available, will be revealing as to whether this is due to some fundamental difference in the OCO-3 measurements or perhaps associated with something particular in the retrieval setup.

Spatial seasonal maps of the total bias correction (in units ppm) are shown in Fig. 16. Although the results are qualitatively different from those seen for the operational OCO-2 B8 data presented in O'Dell et al. (2018), this follows expectations in that here we are working with simulated data that are more internally consistent than real data, especially 
Table 2. Variables and thresholds used for quality filtering in the OCO-3 simulations for nadir-land. The cumulative fraction of passing scenes is also given. Note that the need for the water vapor scale factor (L2FP WV scale) is likely due to a recently discovered bug in the simulator code that introduced a mismatch between the vertical profile in the scene and meteorology files.

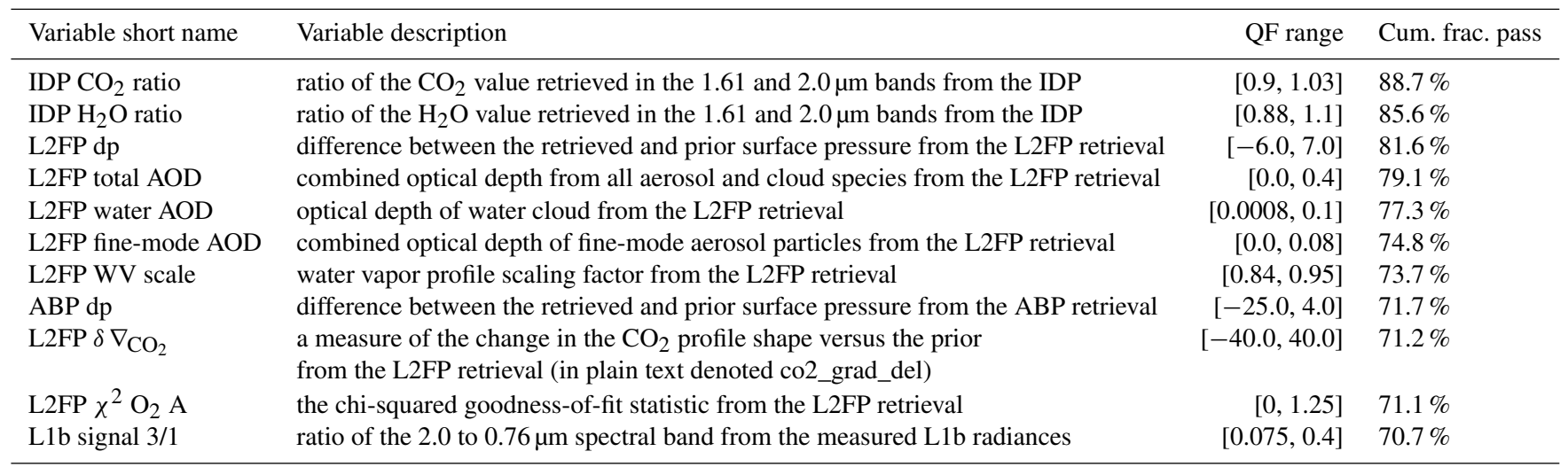

Table 3. Same as Table 2, but for glint-water soundings.

\begin{tabular}{|c|c|c|c|}
\hline Variable short name & Variable description & $\mathrm{QF}$ range & Cum. frac. pass \\
\hline $\mathrm{L} 2 \mathrm{FP} \mathrm{WCO}_{2}$ albedo slope & $\begin{array}{l}\text { albedo slope term of the } 1.61 \mu \mathrm{m} \text { spectral band } \\
\text { from the L } 2 \mathrm{FP} \text { retrieval }\end{array}$ & {$[0.1,100.0]$} & $84.3 \%$ \\
\hline $\mathrm{ABP} d p$ & $\begin{array}{l}\text { difference between the retrieved and prior surface pressure } \\
\text { from the ABP retrieval }\end{array}$ & {$[-50.0,-3.0]$} & $81.7 \%$ \\
\hline L2FP dp & $\begin{array}{l}\text { difference between the retrieved and prior surface pressure } \\
\text { from the L2FP retrieval }\end{array}$ & {$[-5.0,2.0]$} & $75.0 \%$ \\
\hline IDP $\mathrm{CO}_{2}$ ratio & $\begin{array}{l}\text { ratio of the } \mathrm{CO}_{2} \text { value retrieved in the } 1.61 \text { and } 2.0 \mu \mathrm{m} \text { bands } \\
\text { from the IDP retrieval }\end{array}$ & {$[1.0005,1.015]$} & $73.5 \%$ \\
\hline IDP $\mathrm{H}_{2} \mathrm{O}$ ratio & $\begin{array}{l}\text { ratio of the } \mathrm{H}_{2} \mathrm{O} \text { value retrieved in the } 1.61 \text { and } 2.0 \mu \mathrm{m} \text { bands } \\
\text { from the IDP retrieval }\end{array}$ & {$[0.88,1.03]$} & $72.6 \%$ \\
\hline $\mathrm{L} 2 \mathrm{FP} \delta \nabla_{\mathrm{CO}_{2}}$ & $\begin{array}{l}\text { a measure of the change in the } \mathrm{CO}_{2} \text { profile shape versus the prior } \\
\text { from the L2FP retrieval (in plain text denoted co2_grad_del) }\end{array}$ & {$[-30.0,60.0]$} & $72.4 \%$ \\
\hline L2FP total AOD & $\begin{array}{l}\text { combined optical depth from all aerosol and cloud species } \\
\text { from the L2FP retrieval }\end{array}$ & {$[0.0,0.25]$} & $72.2 \%$ \\
\hline Solar zenith angle & $\begin{array}{l}\text { solar zenith angle at the local target } \\
\text { contained in the geolocation }\end{array}$ & {$[0.0,63.0]$} & $70.4 \%$ \\
\hline
\end{tabular}

with respect to spectroscopic lookup tables and meteorology. These results underscore the conclusion that even given nearly perfect alignment of the retrieval model with the truth, there are still retrieval errors that induce biases and scatter into the estimates of $\mathrm{XCO}_{2}$ as explored in detail in Kulawik et al. (2018). This is particularly true of aerosols, which are a continued known source of trouble in virtually all retrievals of greenhouse gases from space (Aben et al., 2007; Butz et al., 2009; Nelson and O’Dell, 2019).

\subsection{Retrieved $\mathrm{XCO}_{2}$ characteristics after filtering and bias correction}

One of the objectives of this study was to analyze the error on the retrieved $\mathrm{XCO}_{2}$ from OCO-3. Here the "actual" error is given as the retrieved value minus the known truth (after applying the averaging kernel correction) and is de- noted $\Delta \mathrm{XCO}_{2}$. The "predicted" error is an L2FP retrieval state-vector parameter that provides the theoretical error due to the combination of measurement noise plus smoothing and interference errors, as discussed in Bösch et al. (2015). The actual errors in the simulated framework are expected to be lower than those seen in OCO-2 operational data, while the predicted errors should be roughly equivalent due to use of a similar instrument model and retrieval algorithm.

As demonstrated in Fig. 17, which shows the histograms of $\triangle \mathrm{XCO}_{2}$ for nadir-land and glint-water data separately, $\triangle \mathrm{XCO}_{2}$ is about $0.5 \mathrm{ppm}$ and effectively corrected by the filtering and bias correction process on an annual average basis. Quality filtering and bias correction reduce the median $\triangle \mathrm{XCO}_{2}$ bias from -0.12 to $-0.02 \mathrm{ppm}$ for land soundings and from 0.23 to $-0.09 \mathrm{ppm}$ for glint-water soundings. The histograms indicate that the filtering process identifies a sig- 

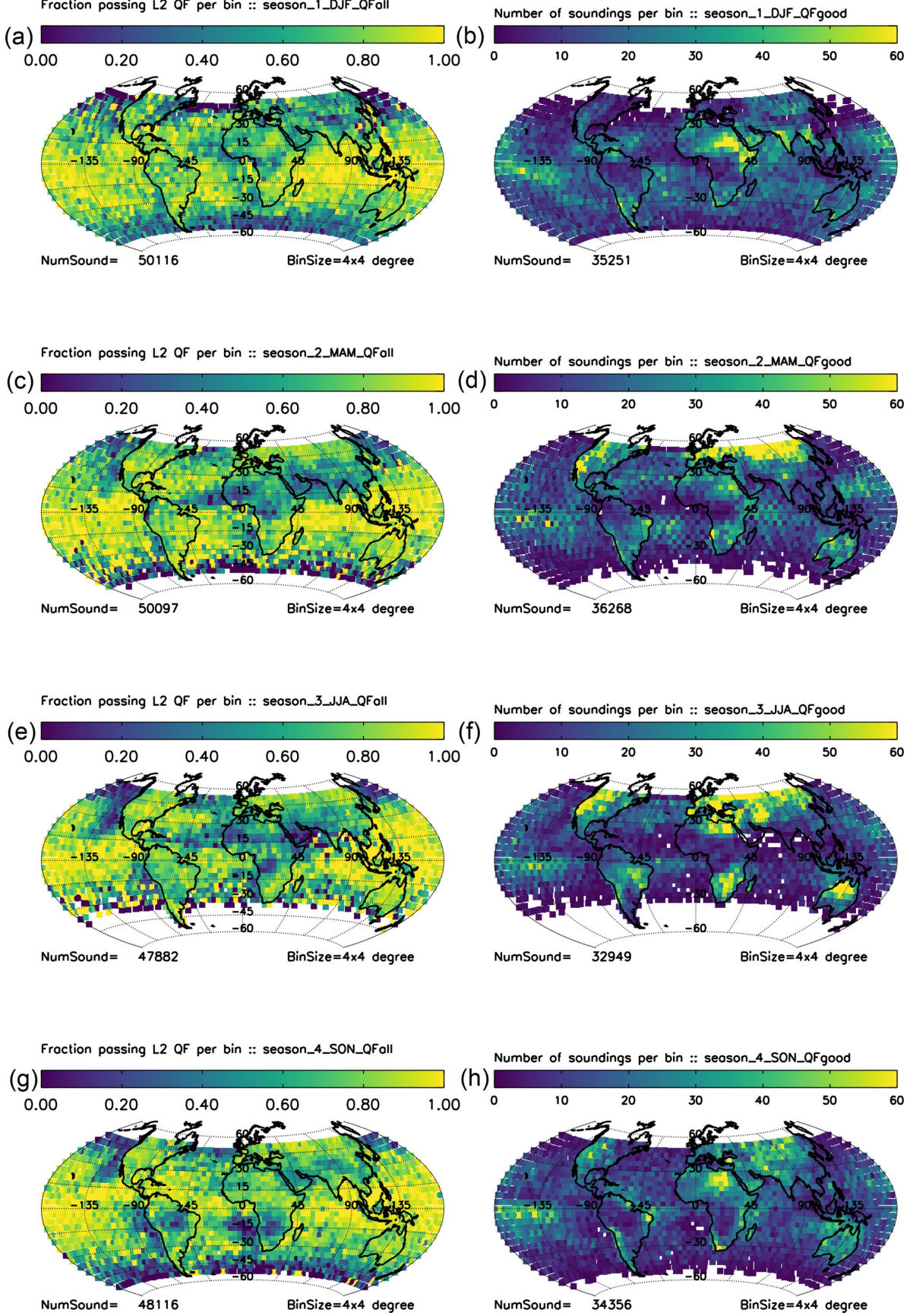

Figure 13. Maps of the seasonal throughput (a, c, e, g) and the resulting sounding densities (b, d, f, h) in $4^{\circ}$ latitude-longitude bins for soundings assigned a good QF. Inflate densities by 240 to account for on-orbit spatiotemporal sampling.

nificant population of glint-water soundings with large negative biases up to about $-12 \mathrm{ppm}$.

The seasonal spatial distributions of $\Delta \mathrm{XCO}_{2}$ are shown in the maps in Fig. 18. These can be compared to Fig. 19 of O'Dell et al. (2018). While the qualitative patterns of actual $\mathrm{XCO}_{2}$ errors are quite different between OCO-2 B8 and simulated OCO-3 data, note that the dynamic range of the scale is much lower for OCO-3 ( $\pm 1 \mathrm{ppm})$ compared to OCO-
2 ( $\pm 3 \mathrm{ppm})$. Again, this follows expectations since the truth proxy for the simulations is the actual truth, while that metric is not available in the real world. Although the ISS latitude varies by $\pm 51.6^{\circ}$, the OCO-3 PMA allows for measurements extending beyond this range to approximately $\pm 55.5^{\circ}$ latitude. However, we found that measurements assigned a good $\mathrm{XCO}_{2} \mathrm{QF}$ are obtained at latitudes less than about $52^{\circ}$, where the solar zenith angle is less than about $73^{\circ}$. 
Table 4. Bias correction parameters for the OCO-3 simulation. Only the prior (dp) terms have units (hPa), while the other parameters are unitless. Again, the need for a water vapor scaling factor bias correction term is likely due to an indexing bug in the L1b simulator code. The "DS" AOD is the combined optical depth of dust and sea salt aerosols.

\begin{tabular}{|c|c|c|c|}
\hline Variable short name & Variable description & $\begin{array}{r}\text { Nadir-land } \\
\text { global bias is } 0.18 \\
\text { BC slope, offset }\end{array}$ & $\begin{array}{l}\text { Glint-water } \\
\text { global bias is } 0.0 \\
\text { BC slope, offset }\end{array}$ \\
\hline L2FP dp & $\begin{array}{l}\text { difference between the retrieved and prior surface pressure } \\
\text { from the L2FP retrieval }\end{array}$ & $-0.20,1.0(\mathrm{hPa})$ & $-0.21,0.0(\mathrm{hPa})$ \\
\hline L2FP WV scale & water vapor profile scaling factor from the L2FP retrieval & $14.0,0.9$ & $\mathrm{n} / \mathrm{a}$ \\
\hline $\mathrm{L} 2 \mathrm{FP} \sqrt{\mathrm{DWS} A O D}$ & $\begin{array}{l}\text { combined optical depth from the dust, water, and sea salt } \\
\text { aerosol species from the L2FP retrieval }\end{array}$ & $-7.6,0.0$ & $\mathrm{n} / \mathrm{a}$ \\
\hline L2FP fine-mode AOD & combined optical depth of fine-mode aerosol particles from & $14.0,0.0$ & $\mathrm{n} / \mathrm{a}$ \\
\hline IDP $\mathrm{CO}_{2}$ ratio & $\begin{array}{l}\text { the } \mathrm{L} 2 \mathrm{FP} \text { retrieval ratio of the } \mathrm{CO}_{2} \text { value retrieved in the } 1.61 \\
\text { and } 2.0 \mu \mathrm{m} \text { bands from the IDP retrieval }\end{array}$ & $\mathrm{n} / \mathrm{a}$ & $-170.0,1.003$ \\
\hline $\mathrm{ABP} d p$ & $\begin{array}{l}\text { difference between the retrieved and prior surface pressure } \\
\text { from the ABP retrieval }\end{array}$ & $\mathrm{n} / \mathrm{a}$ & $-0.053,0.0[\mathrm{hPa}]$ \\
\hline
\end{tabular}

n/a: not applicable.
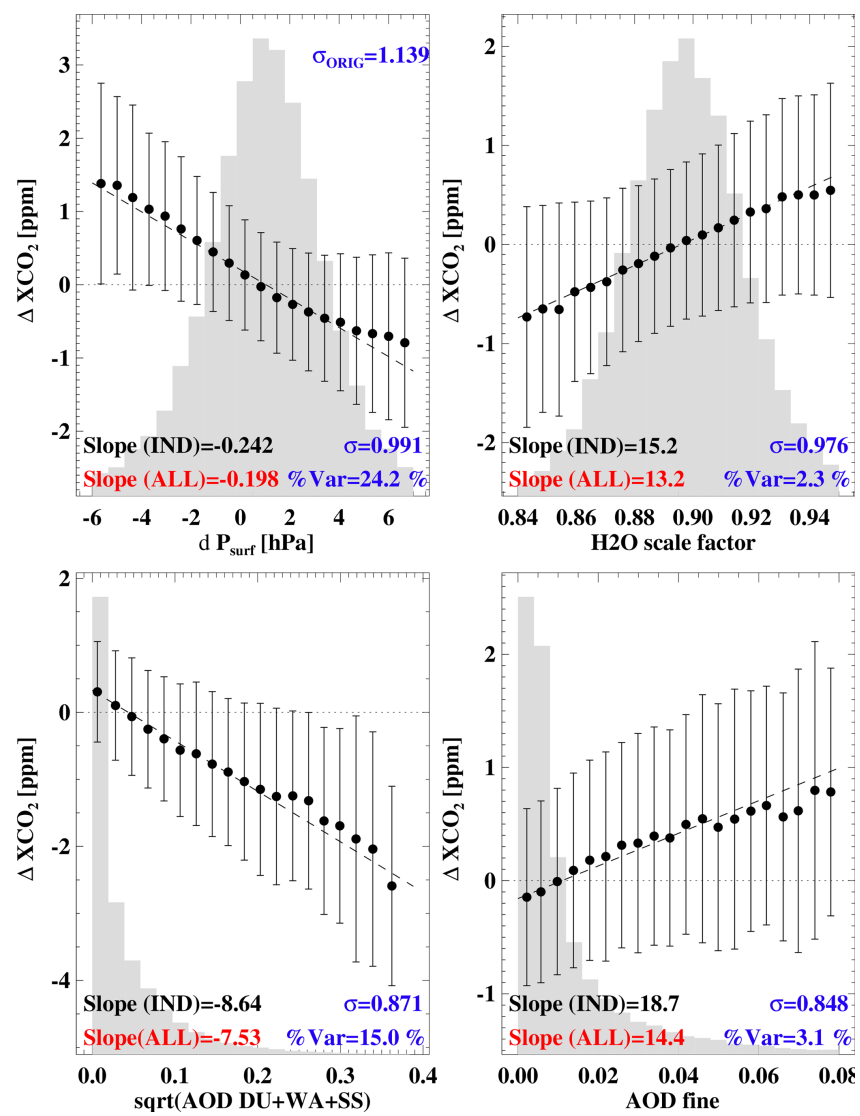

Figure 14. Final bias correction variables used for nadir-land scenes illustrating the correlation of the actual error $\left(\triangle \mathrm{XCO}_{2}\right.$ defined as retrieved - true) as a function of variable value. The leading retrieval parameters that explain the maximum variance for land are the L2FP prior (dp), L2FP $\mathrm{H}_{2} \mathrm{O}$ scale factor, and two L2FP aerosol terms. The original standard deviation $(\sigma)$ of the dataset is given in the upper part of the first panel, with the cumulative reduction in $\sigma$ and percent variance explained given in the lower right.
Table 5. Comparison of the standard deviation $(\sigma)$ in $\mathrm{XCO}_{2}$ before and after QF and BC.

\begin{tabular}{ccc}
\hline & Land-nadir & Ocean-glint \\
\hline$N$ & 96182 & 100029 \\
$\sigma$ raw & $1.88 \mathrm{ppm}$ & $2.15 \mathrm{ppm}$ \\
$\sigma \mathrm{BC}$ & $1.79 \mathrm{ppm}$ & $1.76 \mathrm{ppm}$ \\
$\sigma$ raw QF & $1.14 \mathrm{ppm}$ & $0.67 \mathrm{ppm}$ \\
$\sigma \mathrm{QF}, \mathrm{BC}$ & $0.85 \mathrm{ppm}$ & $0.52 \mathrm{ppm}$ \\
\hline
\end{tabular}

For the OCO-3 simulations, after $\mathrm{QF}$ and $\mathrm{BC}$ have been applied, the errors are largely uncorrelated with any geophysical or retrieval parameters. Specifically, we used the glintwater soundings to check for correlation of both the raw and $\mathrm{BC} \mathrm{XCO}_{2}$ data against latitude, solar zenith angle, polarization angle, SNR (per spectral band), and the true aerosol optical depth. The results are summarized in Table 6. It is worth noting that the true AOD was not used as a bias fitting parameter, yet there is a high reduction in the correlation with $\triangle \mathrm{XCO}_{2}$. The very small slopes, offsets, and linear correlation coefficients that remain after application of the QF-BC indicate that remaining errors in the $\mathrm{XCO}_{2}$ are likely driven by retrieval errors such as the aerosol parameterization (Nelson et al., 2016b).

Shown in Fig. 19 are the OCO-3 actual $\left(\Delta \mathrm{XCO}_{2}\right)$ versus the $\mathrm{L} 2 \mathrm{FP}$ retrieval predicted $\mathrm{XCO}_{2}$ errors comparing the unfiltered raw, the filtered raw, and the filtered and biascorrected data. There is improvement in the performance after filtering is applied, with some additional improvement after application of the bias correction. Results fall nearly on the one-to-one line, with some exception for nadirland soundings when the predicted error falls below about $0.7 \mathrm{ppm}$, in which case the actual error is larger than theory. Overall, these results provide evidence that the filtering and 
Table 6. The slope $(m)$ and offset $(b)$ of a linear least-squares fit (LLS) and Pearson linear correlation coefficient $(R)$ for $\Delta X_{C O}$ versus geophysical parameters before and after application of the QF-BC procedure. Data are for the full annual glint-water soundings only.

\begin{tabular}{lrrrr}
\hline Variable name & $\begin{array}{r}\text { Pre-QF-BC } \\
\text { LLS } m / b\end{array}$ & $R$ & Post-QF-BC \\
& LLS $m / b$ & $R$ \\
\hline Sounding latitude & $-0.000 / 0.520$ & -0.009 & $0.002 /-0.086$ & 0.041 \\
Solar zenith angle & $-0.013 / 0.924$ & -0.255 & $-0.002 / 0.009$ & -0.052 \\
Polarization angle & $-0.016 / 0.928$ & -0.256 & $-0.002 / 0.009$ & -0.052 \\
SNR (oxygen A band) & $-0.000 / 0.513$ & -0.001 & $-0.000 /-0.054$ & -0.002 \\
SNR (weak $\mathrm{CO}_{2}$ band) & $-0.000 / 0.519$ & -0.005 & $-0.000 /-0.054$ & -0.001 \\
SNR (strong $\mathrm{CO}_{2}$ band) & $-0.000 / 0.518$ & -0.005 & $-0.000 /-0.055$ & -0.001 \\
True AOD & $-1.469 / 0.673$ & -0.171 & $-0.029 /-0.053$ & -0.004 \\
\hline
\end{tabular}
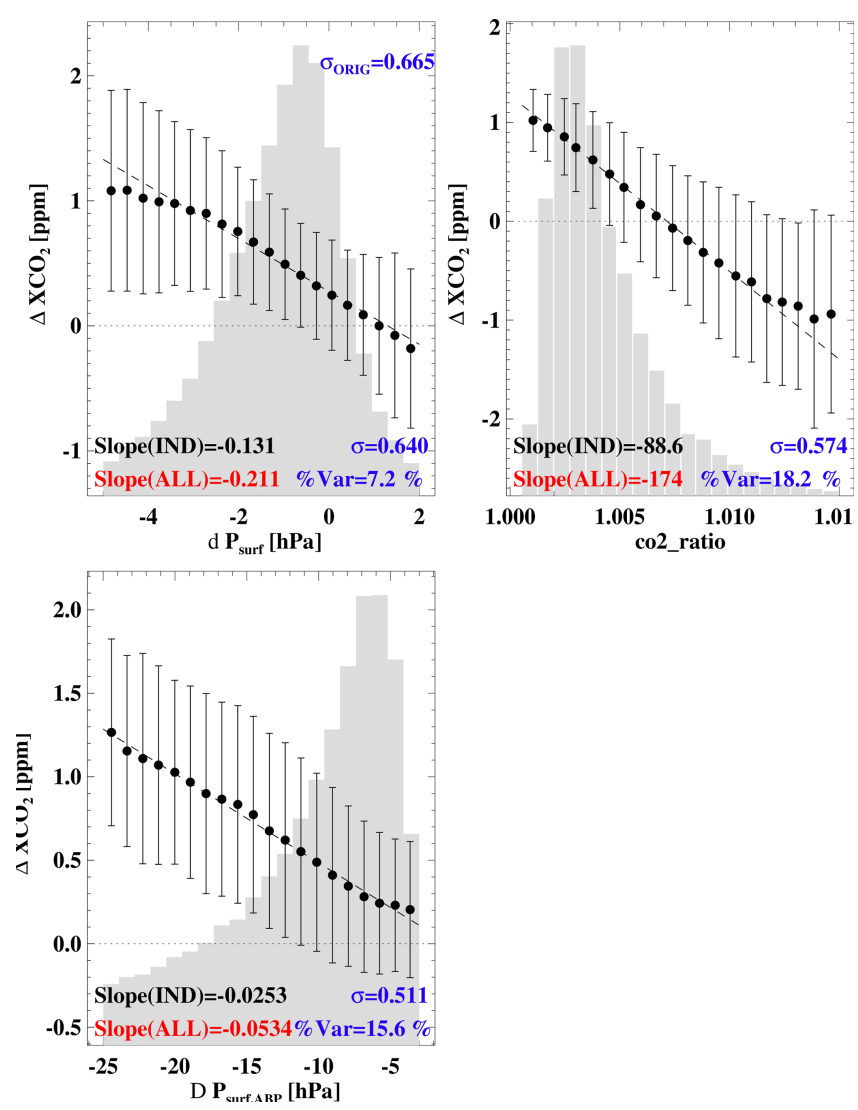

Figure 15. Same as in Fig. 14, but for glint-water scenes. Here the leading retrieval variables that explain the maximum variance are the L2FP dp, the IDP co2_ratio, and the ABP dp_cld.

bias correction methodology is a robust procedure that performs according to theory given a (nearly) perfect truth metric, without additional real-world factors such as imperfect meteorology, spectroscopy, and instrument model.

\subsection{Retrieved SIF characteristics}

Similar to the analysis of $\mathrm{XCO}_{2}$ in the previous section, here we present the IDP SIF relative to the true values and exam- ine both the actual and predicted errors. In order to calculate the actual SIF error (retrieved - true), the L1b truth values, which are calculated at $755 \mathrm{~nm}$ in the simulator code, were first wavelength shifted to match the IDP-retrieved values at 758.65 and $769.95 \mathrm{~nm}$. Note that these channel values denote the center points of the IDP retrieval ranges but are labeled as 757 and $771 \mathrm{~nm}$ throughout the code and analysis for historical purposes as reported in Sect. 2.2 of Sun et al. (2018). For brevity, we only show results for the $757 \mathrm{~nm}$ band, although there is no reason to expect a significant difference in performance in the $771 \mathrm{~nm}$ band.

The retrieval of SIF from space is highly sensitive to instrument noise (Frankenberg et al., 2014). It is therefore a common practice to aggregate some number of soundings, $N$, in order to minimize the random noise. Since these simulations have spatiotemporal sampling of $1 / 240$ of the real expected value, we "noise corrected" our results by scaling the noise as

$\mathrm{SIF}^{\prime}=\mathrm{SIF}+\frac{\text { noise }}{\sqrt{240}}$,

where SIF represents the retrieved values using noiseless radiances, and noise is calculated by differencing SIF from IDP runs with and without instrument noise added to the L1b radiances.

Unlike $\mathrm{XCO}_{2}$ retrievals, the retrieval of SIF using the solar Fraunhofer lines is not highly sensitive to cloud and aerosol contamination (Frankenberg et al., 2012). We therefore did not apply any strict prescreening prior to running the IDP retrieval on the L1b files. Although IDP can in principle retrieve SIF over water, glint-water soundings were ignored since the L1b simulator assumes zero SIF in these cases. Out of the $\sim 337000$ total land soundings approximately $12 \%$ of the IDP retrievals failed outright, leaving $\sim 300000$ for analysis.

Post-processing quality filtering was then applied, which included removal of scenes with $\mathrm{SZA}>70^{\circ}$, for which the actual SIF error became very large. We also removed 49 soundings for which the predicted retrieval noise as a function of the continuum-level radiance fell well outside a smooth fitting criteria. For unknown reasons this small num- 

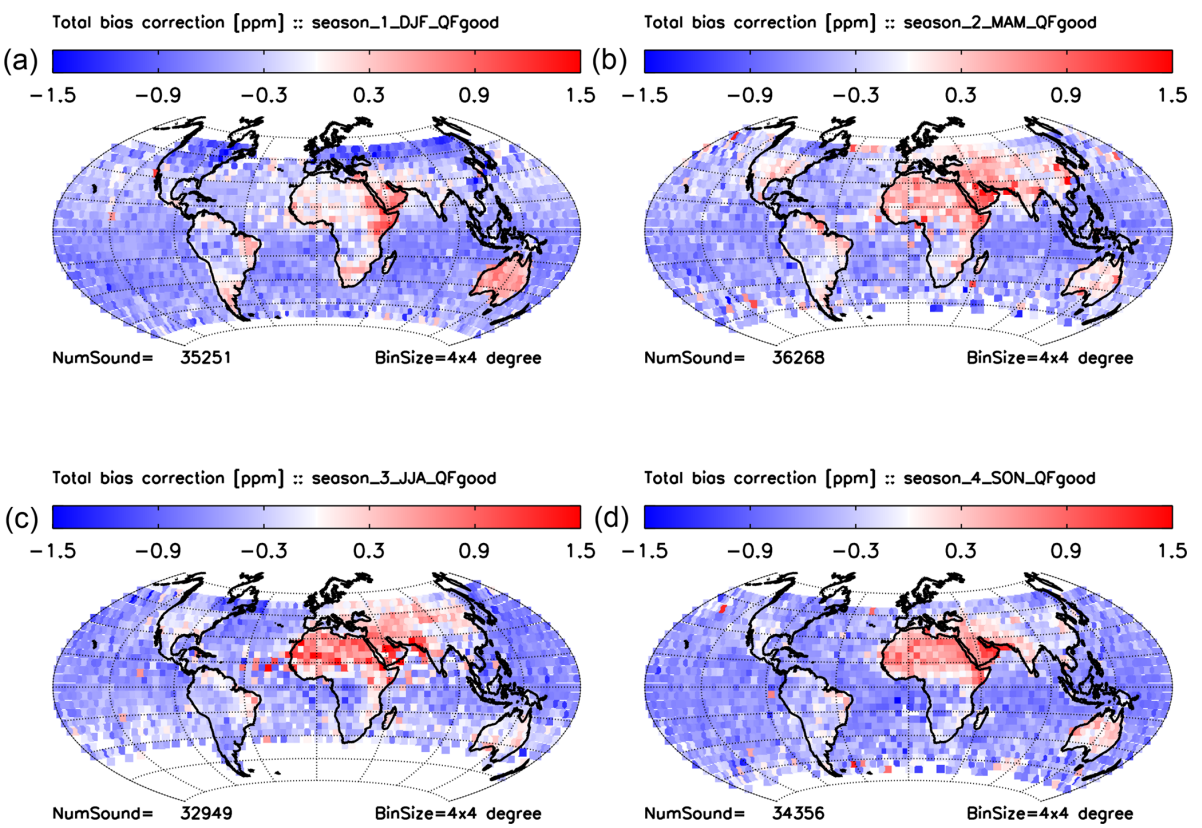

Figure 16. Seasonal maps of the total $\mathrm{XCO}_{2}$ bias correction in $4^{\circ}$ latitude-longitude bins for all soundings assigned a good QF. (a) DJF, (b) MAM, (c) JJA, and (d) SON.
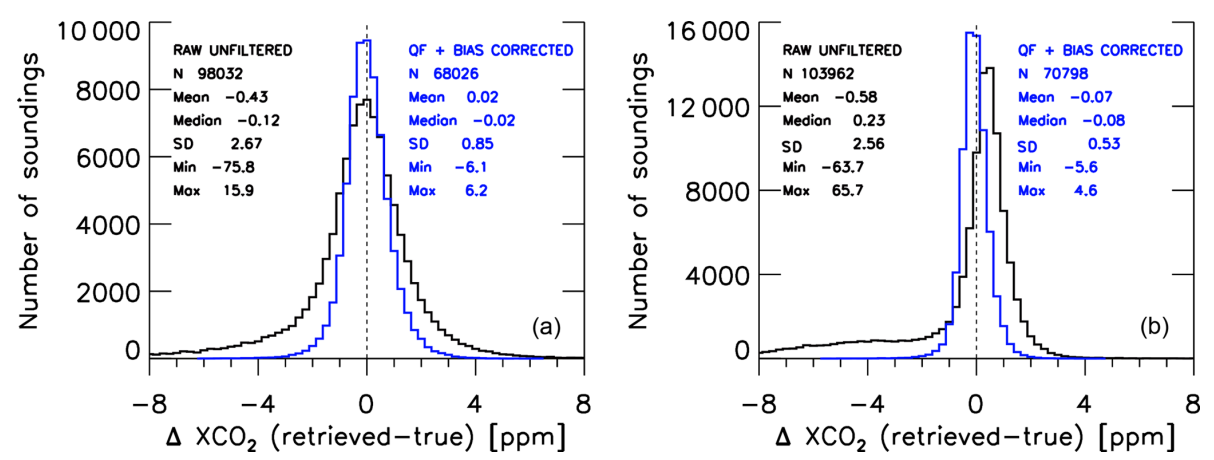

Figure 17. Histograms of the error in $\mathrm{XCO}_{2}$ (retrieved - true) at $0.25 \mathrm{ppm}$ resolution for land (a) and water (b) for the full year of simulations. The raw, uncorrected $\mathrm{XCO}_{2}$ values are shown in black, while the filtered and bias-corrected values are shown in blue.

ber of soundings had very large actual SIF errors. After application of the filtering criteria, approximately 264000 land soundings $\left(88 \%\right.$ of the successful soundings $\left.{ }^{2}\right)$ remained in the annual dataset.

Figure 20a and $\mathrm{b}$ show maps of the true and IDP-retrieved SIF, respectively, for the $757 \mathrm{~nm}$ band for the JJA season, when the Northern Hemisphere land photosynthetic activity is at its annual maximum. The units are expressed in radiance space as Watts per square meter per micron per steradian ( $\mathrm{W} \mathrm{m}^{-2} \mu \mathrm{m}^{-1} \mathrm{sr}^{-1}$ ). SIF typically comprises at the maximum about $1 \%$ to $2 \%$ of the continuum radiance measured at the top of the atmosphere by satellite sensors (Frankenberg et al., 2012). At a gross scale, the true and retrieved

\footnotetext{
${ }^{2}$ It is coincidence that both the fraction of soundings that failed the IDP retrieval and the number that were flagged by our postprocessing filter is $12 \%$.
}

values show the expected patterns, with SIF up to about $1.2 \mathrm{~W} \mathrm{~m}^{-2} \mu \mathrm{m}^{-1} \mathrm{sr}^{-1}$ in densely vegetated tropical regions, when aggregated to $1^{\circ}$ by $1^{\circ}$ bins, and (near) zero SIF over barren deserts, high mountains, and high latitudes.

Although they appear qualitatively similar, the absolute difference in true and retrieved values suggests that the IDP tends to underestimate SIF. This is particularly so for higher fluorescing areas, as seen in Fig. 20c. To better quantify the differences in the retrieved and true values, a fractional difference was calculated after masking out the soundings with true SIF less than $0.2 \mathrm{~W} \mathrm{~m}^{-2} \mu \mathrm{m}^{-1} \mathrm{sr}^{-1}$ to avoid the intractable math of the ratio of two numbers close to zero. As seen in Fig. 20d, the median fractional difference in SIF is $-9 \%$ for this subset of the data, with individual soundings having outliers as large as $-240 \%$. Panels (e) and (f) show the correlation between the true and re- 
(a)

$\Delta \times \mathrm{CO}_{2}$ (retrieved-true) [ppm] :: seoson_1_DJF_QFgood

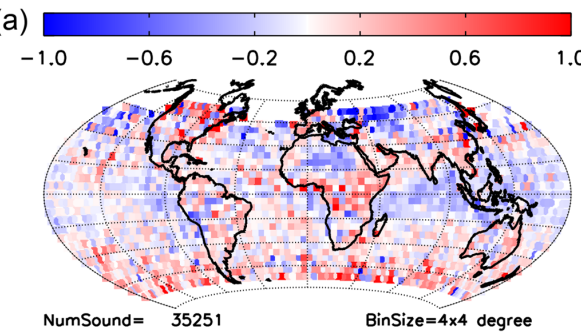

$\Delta \mathrm{XCO}_{2}$ (retrieved-true) [ppm] :: seoson_2_MAM_QFgood

(b)
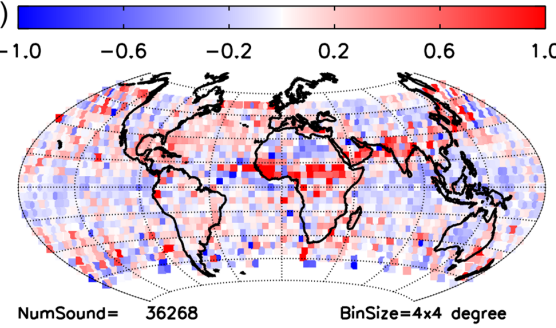

(c)

$\Delta \times \mathrm{CO}_{2}$ (retrieved-true) [ppm] :: seoson_3_JJA_QFgood

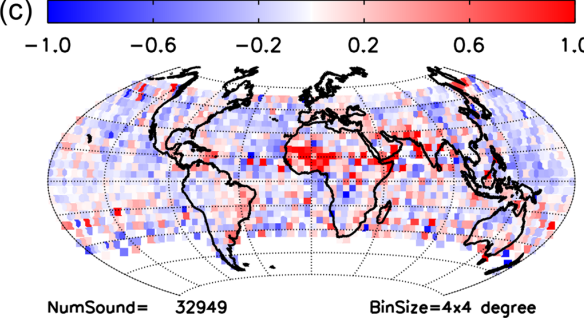

$\Delta \times \mathrm{XO}_{2}$ (retrieved-true) [ppm] :: seoson_4_SON_QF good

(d)

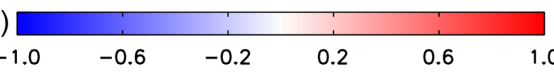

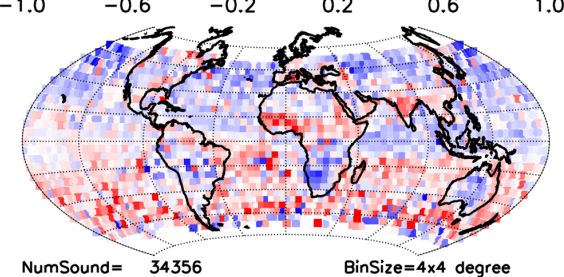

Figure 18. Seasonal maps of delta $\mathrm{XCO}_{2}$ (retrieved - true $[\mathrm{ppm}]$ ) in $4^{\circ}$ latitude-longitude bins after quality filtering and bias correction. (a) DJF, (b) MAM, (c) JJA, and (d) SON.
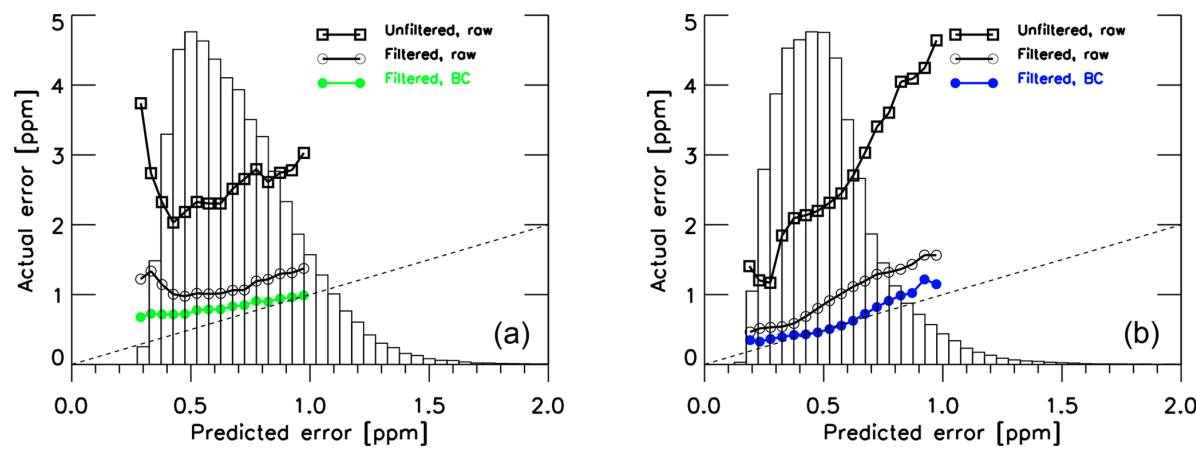

Figure 19. Binned median values of the actual versus predicted $\mathrm{RMS} \mathrm{XCO}_{2}$ error for the full annual dataset for nadir-land (a) and glintwater soundings (b). Each panel shows the unfiltered raw $\mathrm{XCO}_{2}$ (open diamonds), the raw $\mathrm{XCO}_{2}$ for the soundings assigned a good QF (open circles), and the and bias-corrected $\mathrm{XCO}_{2}$ for the soundings assigned a good QF (closed circles). To provide reference, the raw, unfiltered dataset is also displayed as a histogram. The one-to-one line is given as a dashed line.

trieved values for the JJA data with and without the true SIF $<0.2 \mathrm{~W} \mathrm{~m}^{-2} \mu^{-1} \mathrm{sr}^{-1}$. The Pearson linear correlation coefficients are very close to 1 , indicating that the retrieval of SIF from the IDP is expected to perform well for the OCO-3 instrument, as has already been shown for operational OCO2 data (Sun et al., 2017, 2018).

The comparison between the actual (retrieved minus true) and predicted SIF error is shown in Fig. 21. Here we show both the unfiltered, i.e., no quality flag applied, and filtered annual datasets. When the retrieval predicted error is above approximately $0.25 \mathrm{~W} \mathrm{~m}^{-2} \mu \mathrm{m}^{-1} \mathrm{sr}^{-1}$ the actual error is in very close agreement for the filtered data. Below a predicted error of $\simeq 0.25 \mathrm{~W} \mathrm{~m}^{-2} \mu \mathrm{m}^{-1} \mathrm{sr}^{-1}$, the filtered dataset still tends to have a slightly larger value of actual error. For pre- dicted error $<0.25 \mathrm{~W} \mathrm{~m}^{-2} \mu^{-1} \mathrm{sr}^{-1}$ the actual error becomes quite large in the unfiltered dataset.

A comparison of the single-sounding SIF precision between the OCO-3 simulations and the operational B8 OCO-2 data is given in Fig. 22 for both the 757 and $771 \mathrm{~nm}$ windows. For both instruments, the precision is an increasing function of the continuum-level radiance, as explained in Sect. 3.1 of Frankenberg et al. (2014) in association with Fig. 8. The darker the scene, the better the precision due to decreasing noise in the Fraunhofer lines. Overall, both instruments have better precision at the shorter-wavelength channel. This analysis suggests that OCO-3 SIF precision will be 10\%-20\% worse than for OCO-2, which may be directly ascribable to the noisier instrument detectors. Analysis of IDP SIF using 
True L1b SIF $757 \mathrm{~nm}\left(\mathrm{~W} / \mathrm{m}^{2} / \mu \mathrm{m} / \mathrm{sr}\right)$ :: seoson_3_JJA_QFoll_noise-corrected

(a)

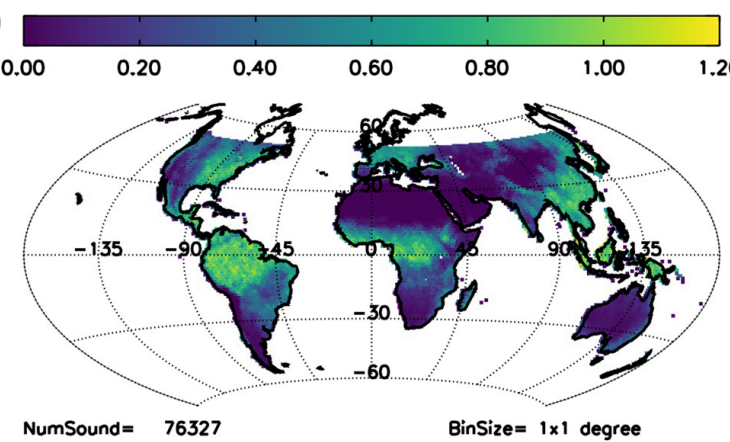

$\Delta$ SIF $757 \mathrm{~nm}\left(\mathrm{~W} / \mathrm{m}^{2} / \mu \mathrm{m} / \mathrm{sr}\right)::$ seoson_3_JJA_QFoll_noise-corrected

(c)

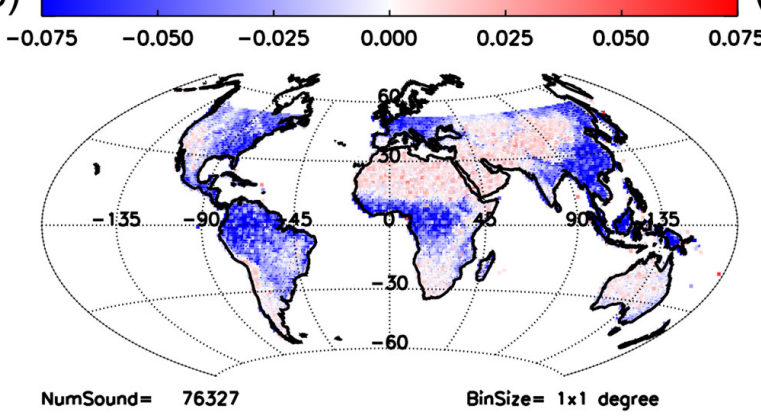

IDP SIF $757 \mathrm{~nm}\left(\mathrm{~W} / \mathrm{m}^{2} / \mu \mathrm{m} / \mathrm{sr}\right)::$ seoson_3_JJA_Qfoll_noise-corrected

(b)

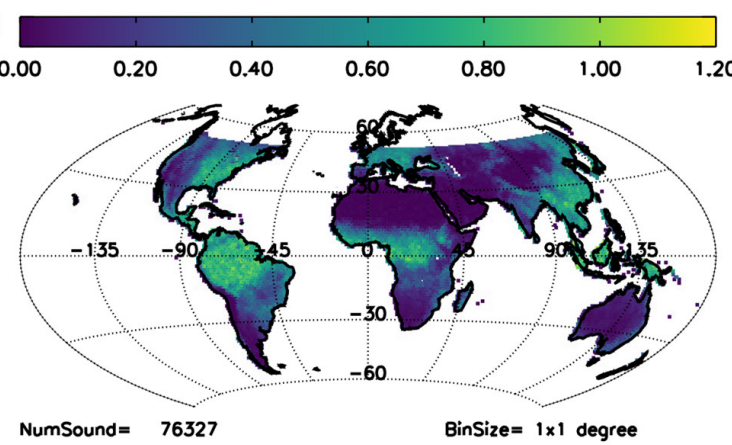

$\Delta$ SIF 757nm (\%) :: seoson_3_JJA_QFoll_noise-corrected

(d)

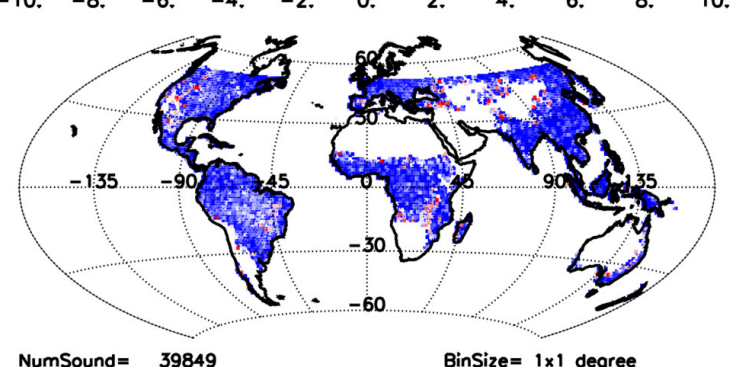

(e)

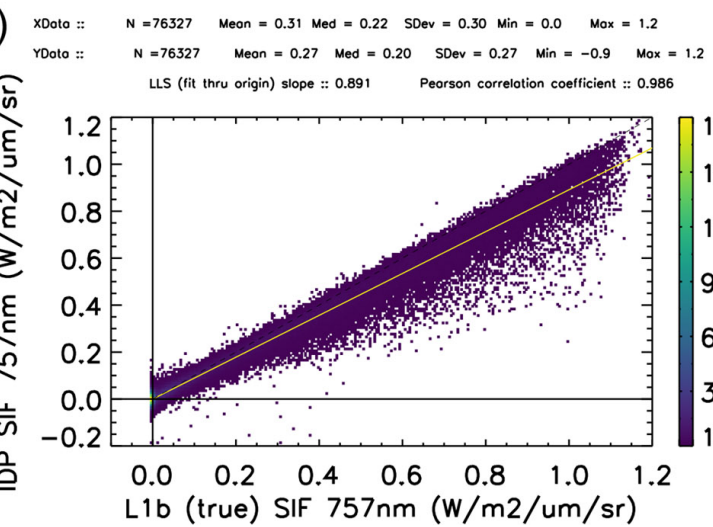

(f) Xooto:: $\quad \mathrm{N}=39849 \quad$ Meon $=0.54 \mathrm{Med}=0.49$ SDev $=0.23 \mathrm{Min}=0.2 \quad \mathrm{Mox}=1.2$

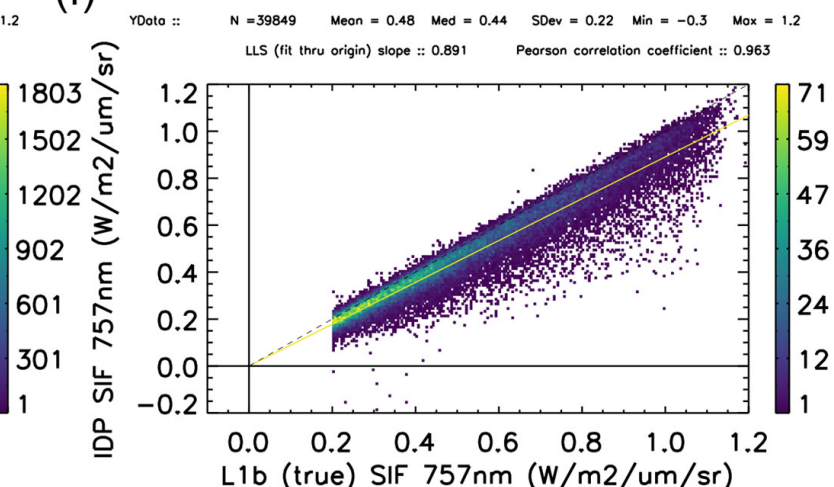

Figure 20. Results comparing the IDP-retrieved and true L1b SIF. These results are from cloudy conditions with noise-corrected SIF at $757 \mathrm{~nm}$. Panels (a, b) and (c, d) show maps gridded to $1^{\circ}$ by $1^{\circ}$ for the JJA soundings assigned a good QF. The true L1b values (a) and the corresponding IDP-retrieved values (b) are both in units $\mathrm{W} \mathrm{m}^{-2} \mu \mathrm{m}^{-1} \mathrm{sr}^{-1}$. The absolute difference between the retrieved and true values (c) and the fractional difference after an additional screening on true SIF $>0.2$ (d). The linear correlation, along with some basic statistics for the full JJA set (e) and the subsetted data (f).

real on-orbit measurements will be used to confirm these results.

\section{Summary}

The work presented here highlights the overall science objectives and expected performance for NASA's upcoming Orbiting Carbon Observatory-3 (OCO-3) mission. OCO-3 will be a hosted payload on the International Space Station, which 


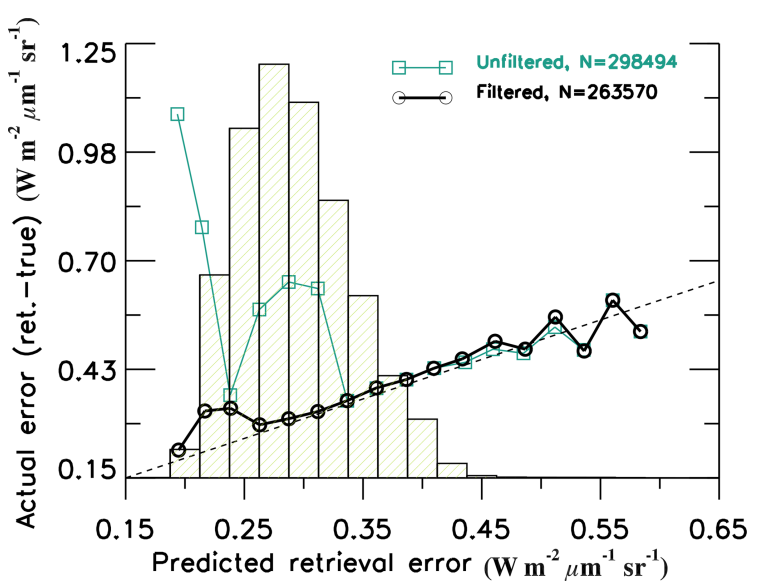

Figure 21. Actual versus predicted IDP SIF error for the unfiltered and filtered annual dataset. This is for the nadir-land retrievals using instrument noise. The histogram shows the filtered data frequency normalized to 1 , with the one-to-one relationship given by the dotted line.

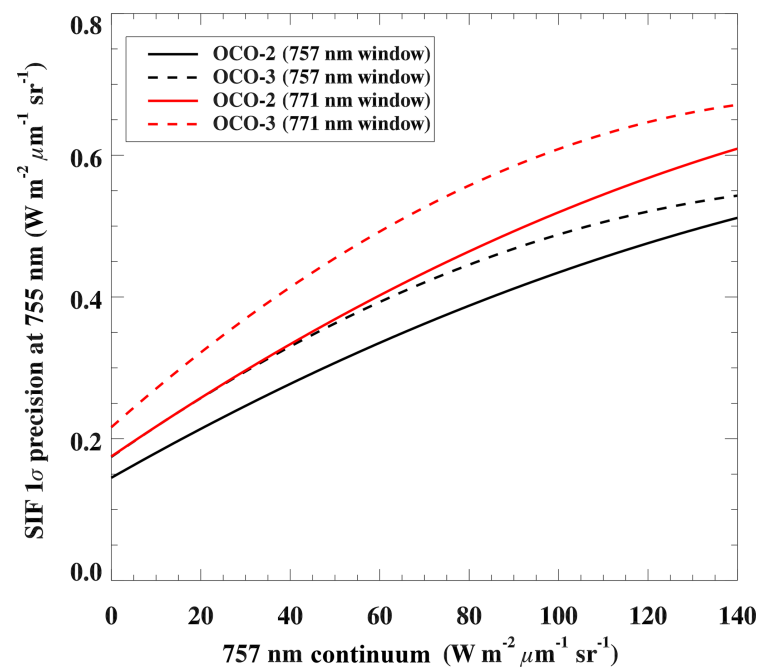

Figure 22. $1 \sigma$ precision of estimated SIF, using both the $757 \mathrm{~nm}$ window (black) and the $771 \mathrm{~nm}$ window (red), for OCO-2 (solid) and OCO-3 (dashed). SIF precision at $755 \mathrm{~nm}$ was estimated from the $757 \mathrm{~nm}(771 \mathrm{~nm})$ value by scaling by a factor of $1.10(1.76)$, following Frankenberg et al. (2015). The OCO-2 values have been evaluated from the IDP posterior uncertainties in the actual SIF data product for an average of all eight footprints. The OCO-3 values have come from an early version of the preflight noise estimates, which are subject to change.

is in a precessing orbit. The launch is currently planned for late April 2019, with a nominal 3-year mission life. While the instrument itself is a duplicate of the operational OCO-2, several features, such as the addition of a pointing mirror assembly and other necessary optical components, will slightly alter the instrument performance. The OCO-3 mission will largely inherit the data algorithms that have been tested and refined using OCO-2.

After introducing the high-level science objectives (which are similar to the OCO-2 mission) and providing a brief overview of the planned measurement strategy, a detailed analysis of a year-long simulation of OCO-3 measurements is presented. The analysis begins with realistic ephemeris and measurement geometries, which are used, along with modeled meteorology and trace gases, to generate synthetic L1b radiances. Cloud-screening preprocessors are used to select soundings to be run through the OCO-2 B8 L2 full physics (L2FP) retrieval, which is the current version of the algorithm that will be adopted for the OCO-3 mission. We performed a quality filtering and bias correction to the retrieved L2FP $\mathrm{XCO}_{2}$, following the methodology described in O'Dell et al. (2018). Overall $\mathrm{XCO}_{2}$ errors, relative to both the true $\mathrm{XCO}_{2}$ and to the predicted error, are assessed. We also present an analysis of the solar-induced chlorophyll fluorescence from the IMAP-DOAS retrieval algorithm and discuss implications of the spatiotemporal sampling from the ISS relative to polar-orbiting satellites.

Generally, these simulations highlight the spatial and temporal sampling expected from OCO-3 aboard the precessing ISS, illustrating how measurements will span a wide range of sunlit hours and have large day-to-day variation in latitudinal sampling. The simulated L1b radiances show signalto-noise characteristics that are generally slightly lower than OCO-2, but still sufficient to accurately estimate $\mathrm{XCO}_{2}$. Over monthly timescales that are typically used in global flux inversion algorithms to estimate sources and sinks of $\mathrm{CO}_{2}$, roughly 2.5 million good quality estimates of $\mathrm{XCO}_{2}$ are expected, spanning latitudes $\sim \pm 52^{\circ}$. An assessment of the error characteristics of $\mathrm{XCO}_{2}$ indicates that they will be comparable to operational OCO-2 data. Furthermore, we demonstrate that the general methodology of L2FP quality filtering and bias correction on the retrieved $\mathrm{XCO}_{2}$, which is being used on operational OCO-2 data, can be used to identify the most useful data and reduce the bias inherent in the full physics retrieval algorithm. In fact, the filtering and bias correction process is necessary in order to meet the measurement objectives.

Retrievals of SIF using the IDP algorithm are also expected to have similar error characteristics compared to OCO-2, especially with respect to error induced by instrument noise. This new set of space-based SIF will be highly informative because of the varying time-of-day sampling so important to characterizing the local behavior of SIF. The dense coverage of latitudes spanning $\sim \pm 52^{\circ}$, where global SIF is most active on an annual scale, is expected to provide a rich dataset to the science community.

Overall, the OCO-3 performance characteristics, as assessed in this simulation, should provide a global dataset that achieves the mission goals and continues the dense, highprecision $\mathrm{XCO}_{2}$, and SIF record from spaceborne measurements. 
Data availability. The simulated data used in this publication are publicly available at the CalTechDATA repository via http://dx.doi. org/10.22002/D1.1222 (Eldering, 2019).

Author contributions. The overall research goals were crafted by AE, with contributions from CWO and TET. RP provided the OCO3 simulated geometry, with input from AE. TET generated the L1b radiances and ran the $\mathrm{ABP}$ and IDP preprocessors. AE ran the L2 FP retrievals, and CWO performed the quality filtering and bias correction procedure. The data analysis and wordsmithing were joint efforts between TET, CWO, and AE. The figures were generated by TET and CWO, with input from AE.

Competing interests. The authors declare that they have no conflict of interest.

Special issue statement. This article is part of the special issue "The 10th International Carbon Dioxide Conference (ICDC10) and the 19th WMO/IAEA Meeting on Carbon Dioxide, other Greenhouse Gases and Related Measurement Techniques (GGMT-2017) (AMT/ACP/BG/CP/ESD inter-journal SI)". It is a result of the 10th International Carbon Dioxide Conference, Interlaken, Switzerland, 21-25 August 2017.

Acknowledgements. A portion of the research described in this paper was carried out at the Jet Propulsion Laboratory, California Institute of Technology, under a contract with the National Aeronautics and Space Administration. The CSU contribution to this work was supported by JPL subcontract 1439002. CarbonTracker CT2015 results provided by NOAA ESRL, Boulder, Colorado, USA from the website at http://carbontracker.noaa.gov (last access: April 2019). We would like to acknowledge the hard work of the OCO-3 calibration team for providing data necessary to generate the L1b simulations. Finally, we thank the two anonymous reviewers that provided useful comments on the paper.

Review statement. This paper was edited by Brigitte Buchmann and reviewed by two anonymous referees.

\section{References}

Aben, I., Hasekamp, O., and Hartmann, W.: Uncertainties in the space-based measurements of $\mathrm{CO}_{2}$ columns due to scattering in the Earth's atmosphere, J. Quant. Spectrosc. Ra., 104, 450-459, 2007.

Basilio, R., Bennett, M., Boland, S., Crisp, D., Eldering, A., Ellis, A., Glavich, T., Gunson, M., Khaki, S., and Pollock, R.: Systems design and implementation of the proposed orbiting carbon observatory- 3 on the international space station's japanese experimental module, Sci. Tech., 114, 321-323, 2013.

Basu, S., Krol, M., Butz, A., Clerbaux, C., Sawa, Y., Machida, T., Matsueda, H., Frankenberg, C., Hasekamp, O., and Aben, I.: The seasonal variation of the $\mathrm{CO}_{2}$ flux over Tropical Asia estimated from GOSAT, CONTRAIL, and IASI, Geophys. Res. Lett., 41, 1809-1815, 2014.

Beer, C., Reichstein, M., Tomelleri, E., Ciais, P., Jung, M., Carvalhais, N., Rodenbeck, C., Arain, M. A., Baldocchi, D., Bonan, G. B., Bondeau, A., Cescatti, A., Lasslop, G., Lindroth, A., Lomas, M., Luyssaert, S., Margolis, H., Oleson, K. W., Roupsard, O., Veenendaal, E., Viovy, N., Williams, C., Woodward, F. I., and Papale, D.: Terrestial gross carbon dioxide uptake: Global distribution and covariation with climate, Science, 329, 834-838, https://doi.org/10.1116/science.1184984, 2010.

Bösch, H., Brown, L., Castano, R., Christi, M., Connor, B., Crisp, D., Eldering, A., Fisher, B., Frankenberg, C., Gunson, M., Granat, R., McDuffie, J., Miller, C., Natraj, V., O’Brien, D., O’Dell, C., Osterman, G., Oyafuso, F., Payne, V., Polonsky, I., Smyth, M., Spurr, R., Thompson, D., and Toon, G.: Orbiting Carbon Observatory (OCO)-2 Level 2 Full Physics, Algorithm Theoretical Basis Document D-55207, Jet Propulsion Laboratory, 2015.

Bösch, H., Toon, G. C., Sen, B., Washenfelder, R. A., Wennberg, P. O., Buchwitz, M., de Beek, R., Burrows, J. P., Crisp, D., Christi, M., Connor, B. J., Natraj, V., and Yung, Y. L.: Space-based near-infrared $\mathrm{CO}_{2}$ measurements: Testing the Orbiting Carbon Observatory retrieval algorithm and validation concept using SCIAMACHY observations over Park Falls, Wisconsin, J. Geophys. Res., 111, D23302, https://doi.org/10.1029/2006JD007080, 2006.

Buchwitz, M., Reuter, M., Schneising, O., Bösch, H., Guerlet, S., Dils, B., Aben, I., Armante, R., Bergamaschi, P., and Blumenstock, T.: The Greenhouse Gas Climate Change Initiative (GHG-CCI): Comparison and quality assessment of near-surface-sensitive satellite-derived $\mathrm{CO}_{2}$ and $\mathrm{CH}_{4}$ global data sets, Remote Sens. Environ., 162, 344-362, https://doi.org/10.1016/j.rse.2013.04.024, 2015.

Buil, C., Pascal, V., Loesel, J., Pierangelo, C., Roucayrol, L., and Tauziede, L.: A new space instrumental concept for the measurement of $\mathrm{CO}_{2}$ concentration in the atmosphere, in: SPIE Remote Sensing, Vol. 8176, International Society for Optics and Photonics, https://doi.org/10.1117/12.897598, 2011.

Butz, A., Hasekamp, O., Frankenberg, C., and Aben, I.: Retrievals of atmospheric $\mathrm{CO}_{2}$ from simulated space-borne measurements of backscattered near-infrared sunlight: accounting for aerosol effects, Appl. Opt., 48, 3322-3336, https://doi.org/10.1364/AO.48.003322, 2009.

Chatterjee, A., Gierach, M., Sutton, A., Feely, R., Crisp, D., Eldering, A., Gunson, M., O'dell, C., Stephens, B., and Schimel, D.: Influence of El Niño on atmospheric $\mathrm{CO}_{2}$ over the tropical Pacific Ocean: Findings from NASA's OCO-2 mission, Science, 358, eaam5776, https://doi.org/10.1126/science.aam5776, 2017.

Connor, B., Bösch, H., McDuffie, J., Taylor, T., Fu, D., Frankenberg, C., O’Dell, C., Payne, V. H., Gunson, M., Pollock, R., Hobbs, J., Oyafuso, F., and Jiang, Y.: Quantification of uncertainties in OCO-2 measurements of $\mathrm{XCO}_{2}$ : simulations and linear error analysis, Atmos. Meas. Tech., 9, 5227-5238, https://doi.org/10.5194/amt-9-5227-2016, 2016.

Connor, B. J., Bösch, H., Toon, G., Sen, B., Miller, C., and Crisp, D.: Orbiting Carbon Observatory: Inverse method and prospective error analysis, J. Geophys. Res., 113, D05305, https://doi.org/10.1029/2006JD008336, 2008. 
Cox, C. and Munk, W. H.: The measurement of the roughness of the sea surface from photographs of the sun's glitter, J. Opt. Soc. Amer., 44, 838-850, https://doi.org/10.1364/JOSA.44.000838, 1954.

Crisp, D., Pollock, H. R., Rosenberg, R., Chapsky, L., Lee, R. A. M., Oyafuso, F. A., Frankenberg, C., O’Dell, C. W., Bruegge, C. J., Doran, G. B., Eldering, A., Fisher, B. M., Fu, D., Gunson, M. R., Mandrake, L., Osterman, G. B., Schwandner, F. M., Sun, K., Taylor, T. E., Wennberg, P. O., and Wunch, D.: The on-orbit performance of the Orbiting Carbon Observatory-2 (OCO-2) instrument and its radiometrically calibrated products, Atmos. Meas. Tech., 10, 59-81, https://doi.org/10.5194/amt-10-59-2017, 2017.

Crowell, S., Baker, D., Schuh, A., Basu, S., Jacobson, A. R., Chevallier, F., Liu, J., Deng, F., Feng, L., Chatterjee, A., Crisp, D., Eldering, A., Jones, D. B., McKain, K., Miller, J., Nassar, R., Oda, T., O’Dell, C., Palmer, P. I., Schimel, D., Stephens, B., and Sweeney, C.: The 2015-2016 Carbon Cycle As Seen from OCO2 and the Global In Situ Network, Atmos. Chem. Phys. Discuss., https://doi.org/10.5194/acp-2019-87, in review, 2019.

Detmers, R., Hasekamp, O., Aben, I., Houweling, S., Leeuwen, T., Butz, A., Landgraf, J., Köhler, P., Guanter, L., and Poulter, B.: Anomalous carbon uptake in Australia as seen by GOSAT, Geophys. Res. Lett., 42, 8177-8184, 2015.

Dubayah, R., Goetz, S., Blair, J. B., Fatoyinbo, T., Hansen, M., Healey, S., Hofton, M., Hurtt, G., Kellner, J., and Luthcke, S.: The global ecosystem dynamics investigation, in: AGU Fall Meeting Abstracts, 2014.

Eldering, A.: Simulated radiance and retrieved variables $\left(\mathrm{XCO}_{2}\right.$ and $\left.\mathrm{SIF}\right)$ for the Orbiting Carbon Observatory3 (OCO-3) Mission (Version 1.0) [Data set], CaltechDATA, https://doi.org/10.22002/d1.1222, 2019.

Eldering, A., O’Dell, C. W., Wennberg, P. O., Crisp, D., Gunson, M. R., Viatte, C., Avis, C., Braverman, A., Castano, R., Chang, A., Chapsky, L., Cheng, C., Connor, B., Dang, L., Doran, G., Fisher, B., Frankenberg, C., Fu, D., Granat, R., Hobbs, J., Lee, R. A. M., Mandrake, L., McDuffie, J., Miller, C. E., Myers, V., Natraj, V., O'Brien, D., Osterman, G. B., Oyafuso, F., Payne, V. H., Pollock, H. R., Polonsky, I., Roehl, C. M., Rosenberg, R., Schwandner, F., Smyth, M., Tang, V., Taylor, T. E., To, C., Wunch, D., and Yoshimizu, J.: The Orbiting Carbon Observatory-2: first 18 months of science data products, Atmos. Meas. Tech., 10, 549563, https://doi.org/10.5194/amt-10-549-2017, 2017a.

Eldering, A., Wennberg, P., Crisp, D., Schimel, D., Gunson, M., Chatterjee, A., Liu, J., Schwandner, F., Sun, Y., and O'Dell, C.: The Orbiting Carbon Observatory-2 early science investigations of regional carbon dioxide fluxes, Science, 358, eaam5745, https://doi.org/10.1126/science.aam5745 2017b.

ESA: Research announcement for ISS experiments relevant to study global climate change: Additional technical information on ISS capabilities and background information, Report, ESA, available at: http://wsn.spaceflight.esa.int/docs/201107/ Annex1-ESA-ISS-CC-AO-Climate-Change.pdf (last access: April 2019), 2011.

Fisher, J., Hook, S., Allen, R., Anderson, M., French, A., Hain, C., Hulley, G., and Wood, E.: ECOSTRESS: NASA's nextgeneration mission to measure evapotranspiration from the International Space Station, in: AGU Fall Meeting Abstracts, 2015.

Frankenberg, C., Butz, A., and Toon, G.: Disentangling chlophyll fluorescence from atmospheric scatting effects in the $\mathrm{O}_{2} \mathrm{~A}$ band spectra of reflected sunlight, Geophys. Res. Lett., 38, L03801, https://doi.org/10.1029/2010GL045896, 2011.

Frankenberg, C., O’Dell, C., Guanter, L., and McDuffie, J.: Remote sensing of near-infrared chlorophyll fluorescence from space in scattering atmospheres: implications for its retrieval and interferences with atmospheric $\mathrm{CO}_{2}$ retrievals, Atmos. Meas. Tech., 5, 2081-2094, https://doi.org/10.5194/amt-5-2081-2012, 2012.

Frankenberg, C., O’Dell, C., Berry, J., Guanter, L., Joiner, J., Kohler, P., Pollock, R., and Taylor, T. E.: Prospects for chlorophyll fluorescence remote sensing from the Orbiting Carbon Observatory-2, Remote Sens. Environ., 147, 1-12, https://doi.org/10.1016/j.rse.2014.02.007, 2014.

Guerlet, S., Basu, S., Butz, A., Krol, M., Hahne, P., Houweling, S., Hasekamp, O., and Aben, I.: Reduced carbon uptake during the 2010 Northern Hemisphere summer from GOSAT, Geophys. Res. Lett., 40, 2378-2383, 2013.

Hulley, G., Hook, S., Fisher, J., and Lee, C.: ECOSTRESS, a NASA Earth-Ventures instrument for studying links between the water cycle and plant health over the diurnal cycle, in: IEEE International Geoscience and Remote Sensing Symposium (IGARSS), https://doi.org/10.1109/IGARSS.2017.8128248, 2017.

Kulawik, S. S., O’Dell, C., Nelson, R. R., and Taylor, T. E.: Validation of OCO-2 error analysis using simulated retrievals, Atmos. Meas. Tech. Discuss., https://doi.org/10.5194/amt-2018-368, in review, 2018.

Kuze, A., Suto, H., Nakajima, M., and Hamazaki, T.: Thermal and near infrared sensor for carbon observation Fourier-transform spectrometer on the Greenhouse Gases Observing Satellite for greenhouse gases monitoring, Appl. Opt., 48, 6716-6733, 2009.

Lindqvist, H., O'Dell, C. W., Basu, S., Boesch, H., Chevallier, F., Deutscher, N., Feng, L., Fisher, B., Hase, F., Inoue, M., Kivi, R., Morino, I., Palmer, P. I., Parker, R., Schneider, M., Sussmann, R., and Yoshida, Y.: Does GOSAT capture the true seasonal cycle of carbon dioxide?, Atmos. Chem. Phys., 15, 13023-13040, https://doi.org/10.5194/acp-15-13023-2015, 2015.

Liu, J., K., B., Lee, M., Henze, D., Bousserez, N., Brix, H., Collatz, G., Menemenlis, D., Ott, L., Pawson, S., Jones, D., and Nassar, R.: Carbon monitoring system flux estimation and attribution: impact of ACOS-GOSAT $\mathrm{XCO}_{2}$ sampling on the inference of terrestrial biospheric sources and sinks, Tellus B, 66, 22486, https://doi.org/10.3402/tellusb.v66.22486, 2014.

Liu, J., Bowman, K. W., Schimel, D. S., Parazoo, N. C., Jiang, Z., Lee, M., Bloom, A. A., Wunch, D., Frankenberg, C., and Sun, Y.: Contrasting carbon cycle responses of the tropical continents to the 2015-2016 El Niño, Science, 358, eaam5690, https://doi.org/10.1126/science.aam5690 2017.

Loveland, T. R. and Belward, A. S.: The IGBP-DIS global $1 \mathrm{~km}$ land cover data set, DISCover: First results, Int. J. Remote Sens., 18 3289-3295, https://doi.org/10.1080/014311697217099, 1997.

Matsunaga, T., Iwasaki, A., Tsuchida, S., Iwao, K., Nakamura, R., Yamamoto, H., Kato, S., Obata, K., Kashimura, O., Tanii, J., Mouri, K., and Tachikawa, T.: HISUI status toward FY2019 launch, in: IGARSS 2018 - 2018 IEEE International Geoscience and Remote Sensing Symposium, 22-27 July 2018, Valencia, Spain, https://doi.org/10.1109/IGARSS.2018.8518639, 2018

Miller, C., Crisp, D., DeCola, P., Olsen, S., Randerson, J., Michalak, A., Alkhaled, A., Rayner, P., Jacob, D., Suntharalingam, P., Jones, D., Denning, A., Nicholls, M., Doney, S., Pawson, S., Bösch, H., Connor, B., Fung, I., O’Brien, D., Salaw- 
itch, R., Sander, S., Sen, B., Tans, P., Toon, G., Wennberg, P., Wofsy, S., Yung, Y., and Law, R.: Precision requirements for space-based $\mathrm{XCO}_{2}$ data, J. Geophys. Res., 112, D10314, https://doi.org/10.1029/2006JD007659, 2007.

Mishchenko, M. I., Cairns, B., Kopp, G., Schueler, C. F., Fafaul, B. A., Hansen, J. E., Hooker, R. J., Itchkawich, T., Maring, H. B., and Travis, L. D.: Accurate monitoring of terrestrial aerosols and total solar irradiance: introducing the Glory Mission, B. Am. Meteor. Soc., 88, 677-692, 2007.

Moore III, B., Crowell, S. M. R., Rayner, P. J., Kumer, J., O’Dell, C. W., O'Brien, D., Utembe, S., Polonsky, I., Schimel, D., and Lemen, J.: The Potential of the Geostationary Carbon Cycle Observatory (GeoCarb) to Provide Multi-scale Constraints on the Carbon Cycle in the Americas, Front. Environ. Sci., 6, 109, https://doi.org/10.3389/fenvs.2018.00109, 2018.

Nakajima, M., Kuze, A., and Suto, H.: The current status of GOSAT and the concept of GOSAT-2, in: SPIE 8533, Sensors, Systems, and Next-Generation Satellites XVI, International Society for Optics and Photonics, https://doi.org/10.1117/12.974954, 2012.

Nassar, R., Hill, T., McLinden, C., Wunch, D., Jones, D., and Crisp, D.: Quantifying $\mathrm{CO}_{2}$ emissions from individual power plants from space, Geophys. Res. Lett., 44, 10045-10053, https://doi.org/10.1002/2017GL074702, 2017.

Nelson, R., Crisp, D., Ott, L., and O'Dell, C.: High-accuracy measurements of total column water vapor from the Orbiting Carbon Observatory-2, Geophys. Res. Lett., 43, 12261-12269, https://doi.org/10.1002/2016GL071200, 2016a.

Nelson, R. R., O’Dell, C. W., Taylor, T. E., Mandrake, L., and Smyth, M.: The potential of clear-sky carbon dioxide satellite retrievals, Atmos. Meas. Tech., 9, 1671-1684, https://doi.org/10.5194/amt-9-1671-2016, $2016 \mathrm{~b}$.

Nelson, R. R. and O'Dell, C. W.: The impact of improved aerosol priors on near-infrared measurements of carbon dioxide, Atmos. Meas. Tech., 12, 1495-1512, https://doi.org/10.5194/amt12-1495-2019, 2019.

O'Brien, D. M., Polonsky, I., O'Dell, C., and Carheden, A.: Orbiting Carbon Observatory (OCO), Algorithm Theoretical Basis Document: The OCO simulator, Technical Report ISSN 0737 5352-85, Cooperative Institute for Research in the Atmosphere, Colorado State University, available at: ftp://ftp.cira.colostate. edu/ftp/TTaylor/publications/20090813_OCO_simulator.pdf (last access: 8 April 2019), 2009.

Oda, T. and Maksyutov, S.: A very high-resolution $(1 \mathrm{~km} \times 1 \mathrm{~km})$ global fossil fuel $\mathrm{CO}_{2}$ emission inventory derived using a point source database and satellite observations of nighttime lights, Atmos. Chem. Phys., 11, 543-556, https://doi.org/10.5194/acp-11543-2011, 2011.

Oda, T., Maksyutov, S., and Andres, R. J.: The Open-source Data Inventory for Anthropogenic $\mathrm{CO}_{2}$, version 2016 (ODIAC2016): a global monthly fossil fuel $\mathrm{CO}_{2}$ gridded emissions data product for tracer transport simulations and surface flux inversions, Earth Syst. Sci. Data, 10, 87-107, https://doi.org/10.5194/essd-10-872018, 2018.

O’Dell, C. W., Connor, B., Bösch, H., O’Brien, D., Frankenberg, C., Castano, R., Christi, M., Eldering, D., Fisher, B., Gunson, M., McDuffie, J., Miller, C. E., Natraj, V., Oyafuso, F., Polonsky, I., Smyth, M., Taylor, T., Toon, G. C., Wennberg, P. O., and Wunch, D.: The ACOS CO2 retrieval algorithm - Part 1: Description and validation against synthetic observations, Atmos. Meas. Tech., 5, 99-121, https://doi.org/10.5194/amt-5-99-2012, 2012.

O’Dell, C. W., Eldering, A., Wennberg, P. O., Crisp, D., Gunson, M. R., Fisher, B., Frankenberg, C., Kiel, M., Lindqvist, H., Mandrake, L., Merrelli, A., Natraj, V., Nelson, R. R., Osterman, G. B., Payne, V. H., Taylor, T. E., Wunch, D., Drouin, B. J., Oyafuso, F., Chang, A., McDuffie, J., Smyth, M., Baker, D. F., Basu, S., Chevallier, F., Crowell, S. M. R., Feng, L., Palmer, P. I., Dubey, M., García, O. E., Griffith, D. W. T., Hase, F., Iraci, L. T., Kivi, R., Morino, I., Notholt, J., Ohyama, H., Petri, C., Roehl, C. M., Sha, M. K., Strong, K., Sussmann, R., Te, Y., Uchino, O., and Velazco, V. A.: Improved retrievals of carbon dioxide from Orbiting Carbon Observatory-2 with the version 8 ACOS algorithm, Atmos. Meas. Tech., 11, 6539-6576, https://doi.org/10.5194/amt11-6539-2018, 2018.

Parazoo, N. C., Bowman, K., Fisher, J. B., Frankenberg, C., Jones, D., Cescatti, A., Perez-Priego, O., Wohlfahrt, G., and Montagnani, L.: Terrestrial gross primary production inferred from satellite fluorescence and vegetation models, Glob. Change Biol., 20, 3103-3121, 2014.

Persh, S., Shaham, Y., Benami, O., Cairns, B., Mishchenko, M. I., Hein, J. D., and Fafaul, B. A.: Ground performance measurements of the Glory aerosol polarimetry sensor, in: Earth Observing Systems XV, vol. 7807, 780703, International Society for Optics and Photonics, https://doi.org/10.1117/12.862029, 2010.

Peters, W., Jacobson, A. R., Sweeney, C., Andrews, A. E., Conway, T. J., Masarie, K., Miller, J. B., Bruhwiler, L. M., Pétron, G., and Hirsch, A. I.: An atmospheric perspective on North American carbon dioxide exchange: CarbonTracker, P. Natl. Acad. Sci. USA, 104, 18925-18930, 2007.

Reuter, M., Bösch, H., Bovensmann, H., Bril, A., Buchwitz, M., Butz, A., Burrows, J. P., O’Dell, C. W., Guerlet, S., Hasekamp, O., Heymann, J., Kikuchi, N., Oshchepkov, S., Parker, R., Pfeifer, S., Schneising, O., Yokota, T., and Yoshida, Y.: A joint effort to deliver satellite retrieved atmospheric $\mathrm{CO}_{2}$ concentrations for surface flux inversions: the ensemble median algorithm EMMA, Atmos. Chem. Phys., 13, 1771-1780, https://doi.org/10.5194/acp-13-1771-2013, 2013.

Richardson, M., Leinonen, J., Cronk, H. Q., McDuffie, J., Lebsock, M. D., and Stephens, G. L.: Marine liquid cloud geometric thickness retrieved from OCO-2's oxygen A-band spectrometer, Atmos. Meas. Tech., 12, 1717-1737, https://doi.org/10.5194/amt12-1717-2019, 2019.

Rosenberg, R., Maxwell, S., Johnson, B. C., Chapsky, L., Lee, R., and Pollock, R.: Preflight radiometric calibration of the Orbiting Carbon Observatory 2, IEEE Trans. Geosci. Remote, 55, 1994 2006, https://doi.org/10.1109/TGRS.2016.2634023, 2017.

Ross, A. N., Wooster, M. J., Bösch, H., and Parker, R.: First satellite measurements of carbon dioxide and methane emission ratios in wildfire plumes, Geophys. Res. Lett., 40, 4098-4102, 2013.

Saha, S., Moorthi, S., Wu, X., Wang, J., Nadiga, S., Tripp, P., Behringer, D., Hou, Y.-T., ya Chuang, H., Iredell, M., Ek, M., Meng, J., Yang, R., Mendez, M. P., van den Dool, H., Zhang, Q., Wang, W., Chen, M., and Becker, E.: The NCEP Climate Forecast System Version 2, J. Climate., 27, 2185-2208, https://doi.org/10.1175/JCLI-D-12-00823.1, 2014.

Schaaf, C. B., Gao, F., Strahler, A. H., Lucht, W., Li, X., Tsang, T., Strugnell, N. C., Zhang, X., Jin, Y., Muller, J.-P., Lewis, P., Barnsley, M., Hobson, P., Disney, M., Roberts, G., Dunderdale, 
M., Doll, C., d'Entremont, R. P., Hu, B., Liang, S., Privette, J. L., and Roy, D.: First operational BRDF, albedo nadir reflectance products from MODIS, Remote Sens. Environ., 83, 135-148, https://doi.org/10.1016/S0034-4257(02)00091-3, 2002.

Schwandner, F. M., Gunson, M. R., Miller, C. E., Carn, S. A., Eldering, A., Krings, T., Verhulst, K. R., Schimel, D. S., Nguyen, H. M., and Crisp, D.: Spaceborne detection of localized carbon dioxide sources, Science, 358, eaam5782, https://doi.org/10.1126/science.aam5782 2017.

Stavros, E. N., Schimel, D., Pavlick, R., Serbin, S., Swann, A., Duncanson, L., Fisher, J. B., Fassnacht, F., Ustin, S., and Dubayah, R.: ISS observations offer insights into plant function, Nat. Ecol. Evol., 1, 1584, https://doi.org/10.1038/s41559-017-0327z, 2017.

Stysley, P. R., Coyle, D. B., Kay, R. B., Frederickson, R., Poulious, D., Cory, K., and Clarke, G.: Long term performance of the High Output Maximum Efficiency Resonator (HOMER) laser for NASA's Global Ecosystem Dynamics Investigation (GEDI) lidar, Optic. Laser Technol., 68, 67-72, https://doi.org/10.1016/j.optlastec.2014.11.001, 2015.

Sun, Y., Frankenberg, C., Wood, J. D., Schimel, D. S., Jung, M., Guanter, L., Drewry, D., Verma, M., Porcar-Castell, A., Griffis, T. J., Gu, L., Magney, T. S., Köhler, P., Evans, B., and Yuen, K.: OCO-2 advances photosynthesis observation from space via solar-induced chlorophyll fluorescence, Science, 358, eaam5747, https://doi.org/10.1126/science.aam5747 2017.

Sun, Y., Frankenberg, C., Jung, M., Joiner, J., Guanter, L., Kohler, P., and Magney, T.: Overview of the solar-induced chlorophyll fluorescence SIF from the Orbiting Carbon Observatory2: Retrieval, cross-mission comparison, and global monitoring for GPP, Remote Sens. Environ., 209, 808-823, https://doi.org/10.1016/j.rse.2018.02.016, 2018.

Taylor, T. E., O’Dell, C. W., Frankenberg, C., Partain, P. T., Cronk, H. Q., Savtchenko, A., Nelson, R. R., Rosenthal, E. J., Chang, A. Y., Fisher, B., Osterman, G. B., Pollock, R. H., Crisp, D., Eldering, A., and Gunson, M. R.: Orbiting Carbon Observatory-2 (OCO-2) cloud screening algorithms: validation against collocated MODIS and CALIOP data, Atmos. Meas. Tech., 9, 973989, https://doi.org/10.5194/amt-9-973-2016, 2016.

Thuillier, G., Hersé, M., Foujols, T., Peetermans, W., Gillotay, D., Simon, P., and Mandel, H.: The solar spectral irradiance from 200 to $2400 \mathrm{~nm}$ as measured by the SOLSPEC spectrometer from the ATLAS and EURECA missions, Sol. Phys., 214, 1-22, 2003.

Toon, G., Blavier, J., Sen, B., Salawitch, R., Osterman, G., Notholt, J., Rex, M., McElroy, C., and Russell, J.: Groundbased observations of Arctic $\mathrm{O}_{3}$ loss during spring and summer 1997, J. Geophys. Res.-Atmos., 104, 26497-26510, 1999.

Winker, D. M., Hunt, W. H., and McGill, M. J.: Initial performance assesement of CALIOP, Geophys. Res. Lett., 34, L19803, https://doi.org/10.1029/2007GL030135, 2007.
Worden, J. R., Doran, G., Kulawik, S., Eldering, A., Crisp, D., Frankenberg, C., O'Dell, C., and Bowman, K.: Evaluation and attribution of OCO- $2 \mathrm{XCO}_{2}$ uncertainties, Atmos. Meas. Tech., 10 2759-2771, https://doi.org/10.5194/amt-10-2759-2017, 2017.

Wunch, D., Toon, G. C., Wennberg, P. O., Wofsy, S. C., Stephens, B. B., Fischer, M. L., Uchino, O., Abshire, J. B., Bernath, P., Biraud, S. C., Blavier, J.-F. L., Boone, C., Bowman, K. P., Browell, E. V., Campos, T., Connor, B. J., Daube, B. C., Deutscher, N. M., Diao, M., Elkins, J. W., Gerbig, C., Gottlieb, E., Griffith, D. W. T., Hurst, D. F., Jiménez, R., Keppel-Aleks, G., Kort, E. A., Macatangay, R., Machida, T., Matsueda, H., Moore, F., Morino, I., Park, S., Robinson, J., Roehl, C. M., Sawa, Y., Sherlock, V., Sweeney, C., Tanaka, T., and Zondlo, M. A.: Calibration of the Total Carbon Column Observing Network using aircraft profile data, Atmos. Meas. Tech., 3, 1351-1362, https://doi.org/10.5194/amt-3-1351-2010, 2010.

Wunch, D., Wennberg, P. O., Toon, G. C., Connor, B. J., Fisher, B., Osterman, G. B., Frankenberg, C., Mandrake, L., O’Dell, C., Ahonen, P., Biraud, S. C., Castano, R., Cressie, N., Crisp, D., Deutscher, N. M., Eldering, A., Fisher, M. L., Griffith, D. W. T., Gunson, M., Heikkinen, P., Keppel-Aleks, G., Kyrö, E., Lindenmaier, R., Macatangay, R., Mendonca, J., Messerschmidt, J., Miller, C. E., Morino, I., Notholt, J., Oyafuso, F. A., Rettinger, M., Robinson, J., Roehl, C. M., Salawitch, R. J., Sherlock, V., Strong, K., Sussmann, R., Tanaka, T., Thompson, D. R., Uchino, O., Warneke, T., and Wofsy, S. C.: A method for evaluating bias in global measurements of $\mathrm{CO}_{2}$ total columns from space, Atmos. Chem. Phys., 11, 12317-12337, https://doi.org/10.5194/acp-11-12317-2011, 2011.

Wunch, D., Wennberg, P. O., Messerschmidt, J., Parazoo, N. C., Toon, G. C., Deutscher, N. M., Keppel-Aleks, G., Roehl, C. M., Randerson, J. T., Warneke, T., and Notholt, J.: The covariation of Northern Hemisphere summertime $\mathrm{CO}_{2}$ with surface temperature in boreal regions, Atmos. Chem. Phys., 13, 9447-9459, https://doi.org/10.5194/acp-13-9447-2013, 2013.

Wunch, D., Wennberg, P. O., Osterman, G., Fisher, B., Naylor, B., Roehl, C. M., O’Dell, C., Mandrake, L., Viatte, C., Kiel, M., Griffith, D. W. T., Deutscher, N. M., Velazco, V. A., Notholt, J., Warneke, T., Petri, C., De Maziere, M., Sha, M. K., Sussmann, R., Rettinger, M., Pollard, D., Robinson, J., Morino, I., Uchino, O., Hase, F., Blumenstock, T., Feist, D. G., Arnold, S. G., Strong, K., Mendonca, J., Kivi, R., Heikkinen, P., Iraci, L., Podolske, J., Hillyard, P. W., Kawakami, S., Dubey, M. K., Parker, H. A., Sepulveda, E., García, O. E., Te, Y., Jeseck, P., Gunson, M. R., Crisp, D., and Eldering, A.: Comparisons of the Orbiting Carbon Observatory-2 (OCO-2) $\mathrm{XCO}_{2}$ measurements with TCCON, Atmos. Meas. Tech., 10, 2209-2238, https://doi.org/10.5194/amt10-2209-2017, 2017.

Yang, D., Liu, Y., Cai, Z., Chen, X., Yao, L., and Lu, D.: First Global Carbon Dioxide Maps Produced from TanSat Measurements, Adv. Atmos. Sci., 35, 621-623, https://doi.org/10.1007/s00376018-7312-6, 2018. 